\title{
Role of N-terminal tau domain integrity on the survival of cerebellar granule neurons
}

\author{
G Amadoro ${ }^{1,2}$, AL Serafino $^{2}$, C Barbato ${ }^{1,2}$, MT Ciotti $^{2}$, A Sacco $^{3}$, \\ $\mathrm{P}_{\text {Calissano }}{ }^{1,2}$ and N Canu ${ }^{*, 1,2}$ \\ 1 Dipartimento di Neuroscienze, Università di Tor Vergata, Via Montpellier 1, \\ Roma 00133, Italia \\ 2 Istituto di Neurobiologia e Medicina Molecolare, CNR, Viale Marx 15, Roma \\ 00137, Italia \\ 3 Laboratorio di Tossicologia Comparata ed Ecotossicologia Istituto Superiore di \\ Sanita, Viale Regina Elena 299, Rome 00161, Italy \\ * Corresponding author: N Canu, Dipartimento di Neuroscienze, Università di \\ Tor Vergata, Via Montpellier 1, 00133 Roma, Italia and c/o Istituto di \\ Neurobiologia e Medicina Molecolare, Viale Marx 15, 00137 Roma, Italia. \\ Tel: + 39-6-86090287; Fax: + 39-6-86090370; E-mail: n.canu@ in.rm.cnr.it
}

Received 29.4.03; revised 03.7.03; accepted 14.7.03; published online 14.11.03 Edited by RA Knight

\begin{abstract}
Although the role of the microtubule-binding domain of the tau protein in the modulation of microtubule assembly is widely established, other possible functions of this protein have been poorly investigated. We have analyzed the effect of adenovirally mediated expression of two fragments of the $\mathrm{N}$ terminal portion - free of microtubule-binding domain - of the tau protein in cerebellar granule neurons (CGNs). We found that while the expression of the tau (1-230) fragment, as well as of full-length tau, inhibits the onset of apoptosis, the tau (144) fragment exerts a powerful toxic action on the same neurons. The antiapoptotic action of tau (1-230) is exerted at the level of Akt-mediated activation of the caspase cascade. On the other hand, the toxic action of the (1-44) fragment is not prevented by inhibitors of CGN apoptosis, but is fully inhibited by NMDA receptor antagonists. These findings point to a novel, physiological role of the $\mathrm{N}$-terminal domain of tau, but also underlay that its possible proteolytic truncation mediated by apoptotic proteases may generate a highly toxic fragment that could contribute to neuronal death.

Cell Death and Differentiation (2004) 11, 217-230. doi:10.1038/ sj.cdd. 4401314

Published online 14 November 2003
\end{abstract}

Keywords: tau; apoptosis; necrosis; Alzheimer's disease; depolarization; cerebellar granule neurons

Abbreviations: CGNs, cerebellar granule neurons; MTs, microtubules; PLC, phospholipase; $\mathrm{PIP}_{2}$, phosphatidylinositolbiphosphate; AD, Alzheimer's disease; NTF, neurofibrillary tangles; $\beta$-Gal, $\beta$-galactosidase; IGF, insulin-like growth factor; ROS, reactive oxygen species; SOD, superoxide dismutase; PI3kinase, phosphatidylinositol-3-kinase; GSK3 $\beta$, glycogen synthase kinase-3 $\beta$; MOI, multiplicity of infection; DIV, days in vitro; Ac-DEVD-MCA, Ac-Asp-Glu-Val-Asp-7-amido-4-methylcoumarin; Ac-VEID-MCA, Ac-Val-Glu-lle-Asp-7-amido-4-methyl- coumarin; BME, basal medium Eagle; FCS, fetal calf serum; zVAD-fmk, benzyloxycarbonyl-Val-Ala-Asp-fluoromethylketone; $\mathrm{PCR}$, polymerase chain reaction

\section{Introduction}

Tau comprises a family of microtubule (MT)-associated proteins that are generated from alternatively spliced transcripts derived from a single gene with 13 exons. ${ }^{1,2}$ These isoforms differ by the presence or the absence of two types of inserts in their $\mathrm{N}$-terminal domain and three or four nonhomologous repeats in their half-carboxyl domain. The functional characterization of tau has been mainly focused on the property to interact with MTs via its C-terminal domain and to modulate their state of assembly, thus playing an important role in neuronal morphogenesis, maintenance of axonal shape, and transport of cellular organelles. ${ }^{3,4}$ The functional role of the $\mathrm{N}$-terminal domain of tau, on the contrary, is largely unexplored. It has been hypothesized that the $\mathrm{N}$ terminal domain operates as a molecular transducer between cytoplasmic membrane components and MTs having an important role in neurite formation during differentiation of the PC12 cell line. ${ }^{5}$ It likely plays a role in the phospholipase (PLC) $-\gamma$ signal transduction pathway, as suggested by the finding that tau coimmunoprecipitates with active PLC- $\gamma$, 7 and that seven putative binding sites for the SH3-binding domain of PLC- $\gamma$ are present in the $\mathrm{N}$-terminal tau region. ${ }^{8}$ Tau also binds directly or indirectly to phosphatidylinositol biphosphate $\left(\mathrm{PIP}_{2}\right)$ that serves as a precursor of diacyglicerol and inositol triphosphate, leading to the activation of PLC $\gamma$, of PKC, and increase in cytosolic calcium. ${ }^{9}$

The proper function of tau depends upon a precise equilibrium between different isoforms and its state of phosphorylation. An imbalance among these isoforms is accompanied by tauopathies, among which Alzheimer's disease (AD) is the most prominent. In these pathologies, tau undergoes a series of post-translational changes including abnormal phosphorylation, glycosylation, ${ }^{10-12}$ glycation, ${ }^{13}$ and truncation, ${ }^{14}$ which may render tau more prone to form aggregated structures. Studies from different 'in vitro' models of neuronal apoptosis as well as from AD samples suggest that proteases activated during apoptosis may cause tau truncation. It has been reported, for example, that tau is cleaved by caspase-3 in its C-terminal domain, ${ }^{15-17}$ while studies on $A D$ samples have reported that caspases cleave the $\mathrm{N}$-terminal tau domain, ${ }^{18}$ and that this event may precede the aggregation of tau into neurofibrillary tangles (NTF). Moreover, transfection of neuronal cells with C-terminal caspase-3 generated tau fragment ${ }^{16,17}$ and with different fragments encompassing its C-terminal domain ${ }^{17}$ induces cell death, suggesting that truncated forms of tau can operate as toxic agents of a selfpropagating intracellular process of neuronal death.

Since little is known about the role of the $\mathrm{N}$-terminal tau domain on neuronal survival, we investigated how the 
adenovirally mediated expression of tau's $\mathrm{N}$-terminal domains could affect the viability of CGNs or their response to apoptotic stimuli, which previous studies have shown to affect tau and MT stability also. ${ }^{15}$

Here we report that the exogenous overexpression of the $\mathrm{N}$ terminal domain (1-230) can be either neuroprotective or neurotoxic according to its length. Thus, the exogenous overexpression of tau (1-230) as well as full-length tau exerts an antiapoptotic effect probably at the level of Akt activity. In contrast, the $\mathrm{N}$-terminal (1-44) tau fragment exerts a marked toxic action involving glutamate receptors, eventually leading to a necrotic-type death.

These findings indicate a hitherto unrecognized physiological role of intact tau on the side of its $\mathrm{N}$-terminal domain, and they also underline the potential toxic action of this domain whenever tau undergoes a proteolytic attack leading to the cytoplasmic dispersion of some of its shorter $\mathrm{N}$-terminal fragments.

\section{Results}

\section{Myc-epitope tags do not impair the property of exogenous tau to bind to MTs}

To validate the use of the Ad-myc-tau protein (Figure 1) as an amended reporter of native tau, we investigated if the 6-myc epitope tags at the $\mathrm{N}$-terminal of exogenously expressed tau would alter or influence the ability of tau to bind and codistribute with MTs. For this purpose, since the fine structure of MTs in CGNs is barely visible due to the small cytoplasmic surface and large nuclear compartment (see Figure 3), we resorted to MDCK cells, which are more suitable for this purpose. These cells were infected with Ad-myc tau vectors and double immunolabeled -2 days post infection with a monoclonal antibody against $\alpha$-tubulin and a polyclonal antibody against the myc epitope tags. Only the tau signal produced by tau (1-441) codistributed with the MTs over the entire length, as evidenced by the tubulin immunostaining
(Figure 2a, b). On the contrary, the myc-tau signal generated by tau (1-230) colocalized only partially with the total net of MTs (Figure 2c, d), consistent with the presence of only a putative weak MT interaction site in this fragment. ${ }^{19,20}$ Moreover, the pattern of codistribution of tau (1-441) with MTs was also preserved after the removal of its soluble fraction from transfected MDCK (Figure $2 a^{\prime}, b^{\prime}$ ); in contrast, the signal produced by the expression of tau (1-230) was totally abolished by this treatment (Figure $2 c^{\prime}, d^{\prime}$ ), indicating that this domain is not, or loosely, bound to MTs.

These observations indicate that the tau (1-441) fusion protein binds to MTs and colocalizes with MTs, in a manner indistinguishable from that of wild-type tau, as previously reported for other tag-tau proteins. ${ }^{20,21}$

\section{Expression of myc-tau proteins}

To investigate how the $\mathrm{N}$-terminal domain of the tau protein affects neuronal viability, three cDNAs based on the longest human tau isoform were cloned into an adenovirus vector for expression in CGNs. An adenoviral construct encoding Lac Z was used as a negative control and in order to test the efficiency of adenovirus-mediated gene transfer in our cellular system. Neurons were infected at 4 days in vitro (DIV) with 30 multiplicity of infection (MOI) of Ad-LacZ, and $\beta$-galactosidase activity was measured at 6 DIV. In control cultures, no $\beta$ galactosidase activity was detected, while about $60 \%$ of AdLacZ-infected neurons were $\beta$-galactosidase positive (data not shown).

We tested the expression of the exogenous tau proteins by Western blot analysis and immunocytochemistry. Since the constructs are myc-tagged, an anti-myc antibody was used to assess their expression (evaluated with the mAb 9E10), as compared to the internal pool of tau evaluated with the mAb TAU 1. As shown in Figure 3a, neurons infected with $30 \mathrm{MOI}$ of adenoviral constructs encoding tau (1-230) and tau (1-441) expressed exogenous proteins at comparable levels.

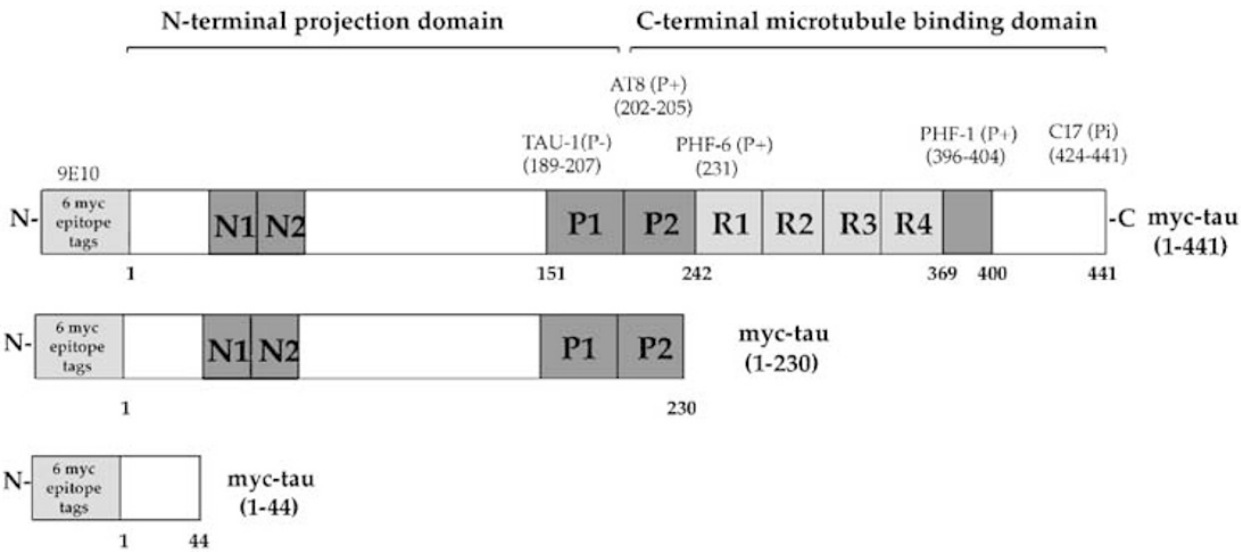

Figure 1 Tau constructs employed in this study. Three constructs have been used in this study: Ad myc-tau (1-441), Ad-myc tau (1-230), and Ad-myc tau (1-44). All constructs are derived from the longest human tau isoform (htau 40), and have been expressed with 6 myc epitope tags fused to the aminoterminus. The longest human tau isoform consists of 441 amino-acid residues, and can be divided into an $\mathrm{NH}_{2}$-terminal projection domain and a $\mathrm{COOH}$-terminal MT-binding domain containing four imperfect repeats (R1-R4) and a basic proline-rich sequence on either sites that acts as an MT-targeting domain (P1 e P2). The N1 and N2 inserts at N-terminus can be alternatively spliced. The diagram also shows the epitope locations of the antibodies used in this study. C17 recognizes the primary structure of the tau sequence independent of phosphorylation status (indicated as Pi). AT8, PHF1, and PHF6 recognize phosphorylated epitopes (P + ), whereas TAU-1 binds to a dephosphorylated epitope $(\mathrm{P}-)$ 


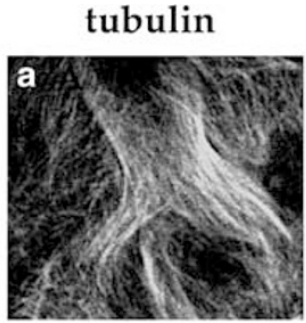

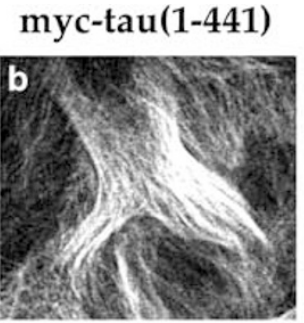

tubulin
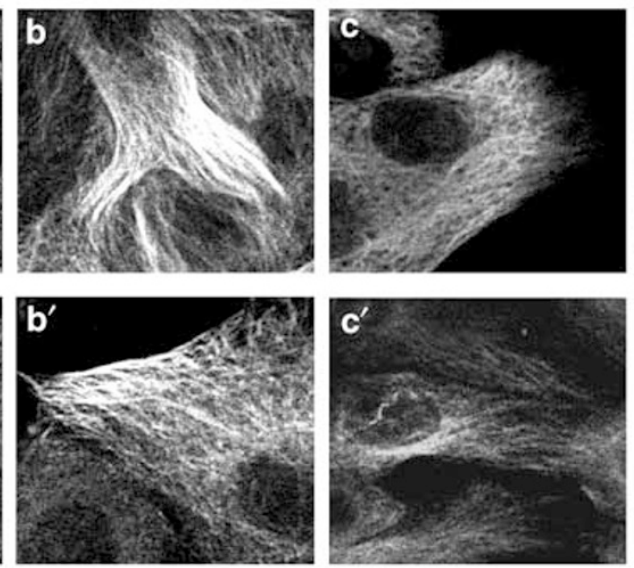
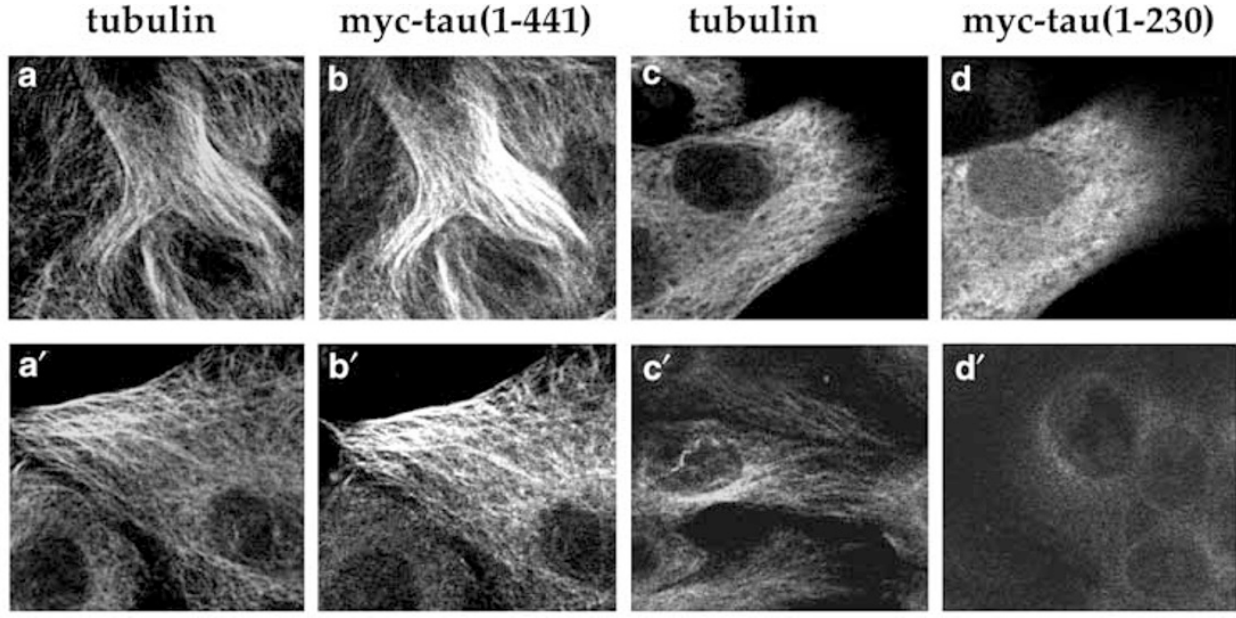

Figure 2 Myc-tau (1-441) fusion protein colocalizes with MTs. MDCK cells were fixed 36h after infection with Ad myc-tau (1-441)- and Ad-myc tau- (1-230) expressing adenovirus vectors at $30 \mathrm{MOI}$, and double immunostained with an antibody to $\alpha$-tubulin and with an antibody to the myc-tau fusion protein. Fluorescence stainings of myc-tau and cellular tubulin were taken after a combined fixation and permeabilization protocol (a-d) or after an extraction and fixation protocol $\left(\mathbf{a}^{\prime}-\mathbf{d}^{\prime}\right)$ to evaluate the MT association. Fluorescent images were taken in a laser confocal microscope (Leica TCS 4D system, equipped with $\times 1001.3 \times 10^{6}$ oil-immersion objective, optical section $1 \mu \mathrm{M})$. Optical sections were stereopaired and three-dimensional reconstituted

Only tau (1-441) displayed the predicted molecular weight of $70 \mathrm{kDa}$, while tau (1-230) ran at $50-52 \mathrm{kDa}$, a molecular weight higher than that expected, but in agreement with a previous report. ${ }^{5}$ In order to quantify the amount of exogenous tau expression accurately, cellular homogenates were pretreated with alkaline phosphatase before application to the gel. In tau (1-441) and tau (1-230) cells infected with $30 \mathrm{MOI}$, the level of expression - monitored using mAb TAU-1 - was $\sim$ two-fold higher, relative to the endogenous tau used as an internal standard for normalization (not shown). It is noteworthy that while the evaluation of the amount of tau (1-230) and tau (1-441) was performed from a lysate of $2.5 \times 10^{5}$ neurons, in order to have a comparable quantitative amount of tau (1-44), it was necessary to load the lysate of $2.5 \times 10^{6}$ neurons. This finding is most probably attributable, as will be discussed below, to the marked toxic action of this fragment with the consequent death of most neurons.

Analysis by laser-scanning microscopy (Figure 3b) showed that tau (1-441) expressing neurons exhibited the typical pattern of tau localization, which includes the axon, and a small ring of cytoplasm. This staining endured after removing the soluble tau fraction, indicating, as also reported for infected MDCK, that tau (1-441) maintains the ability to interact with the MT network. The overexpression of tau (1230) resulted in a relatively strong staining of the soma and of a partial portion of the axon; this pattern of localization disappeared after the removal of the soluble protein pool, as also shown in Figure 2. At variance with this pattern of expression, tau (1-44) uniformly distributed in the cell body, with the exclusion of dendrites and axons. As also reported for tau (1-230), the staining was abolished after the removal of the soluble pool of proteins. Furthermore, tau (1-44) expression was detectable as a strong immunostaining only for a limited period after infection, and it progressively disappeared. At $48 \mathrm{~h}$ post infection, no or few neurons were still positive, probably due to the progressive cell death induced by the overexpression of this fragment (not shown). We estimated that about $50-60 \%$ of neurons was consistently transfected and expressed myc tau, although the level of expression was not homogenous in all cells, as evaluated by immunofluorescence analysis.

\section{The N-terminal tau fragments differentially affect cell viability}

We analyzed whether the expression of tau (1-230), tau (1-44), and tau (1-441) altered the viability of CGNs. For this purpose, neurons were infected at 4 DIV at different MOI with recombinant adenovirus tau vectors. At 6 DIV, neuronal survival was evaluated by the MTT assay, and by counting the number of intact nuclei. Control cultures were either infected with the LacZ construct or left uninfected. As reported in Figure $4 \mathrm{a}$, the expression of tau (1-230) and the full-length tau fragment caused a modest reduction of neuronal viability by a maximum of $20 \pm 6.8$ and $18 \pm 7.9 \%(n=3)$, respectively, after $48 \mathrm{~h}$ post infection. The Ad-Lac $\mathrm{Z}$ vector alone caused a reduced viability in the range of $10 \pm 5.6 \%(n=3)$.

In contrast, a marked cell death, which was proportional to the extent of infected cells, was observed in cells expressing tau (1-44). Thus, cell viability was reduced to $40 \%$ at $\mathrm{MOI} 10$, and progressively declined to $10 \%$ at $\mathrm{MOI} 50$ with intermediate levels within these two extremes. It is remarkable that none of the survival neurons were 9E10 positive (not shown).

It has recently been demonstrated that the overexpression of the longest human tau isoform in animal and fly models induces neurodegeneration and neuronal loss in a timedependent manner. ${ }^{22-24}$ Furthermore, the overexpression of pseudohyperphosphorylated tau in neuronal cells causes apoptotic death. ${ }^{25}$ We therefore monitored the neuronal viability (Figure 4b) and the myc-tau expression (Figure 4c) at different times after infection. Neurons overexpressing tau (1-230) and tau (1-441) constructs remained viable under the same culture conditions for 4 days post infection, showing no 
a

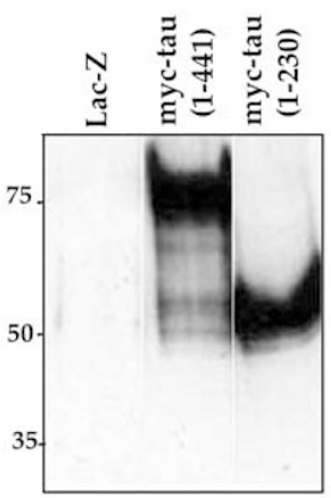

9E10

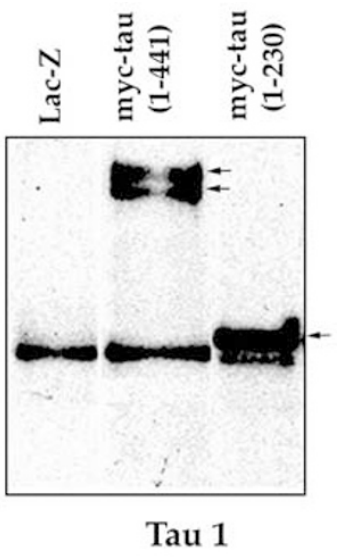

Tau 1

C

Lac-Z
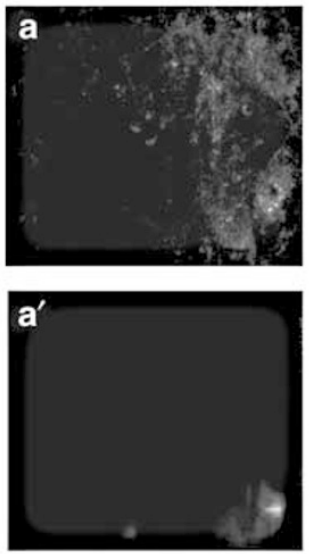

myc-tau (1-441)
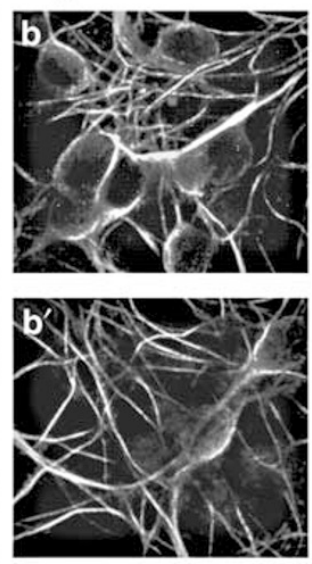

myc-tau (1-230)
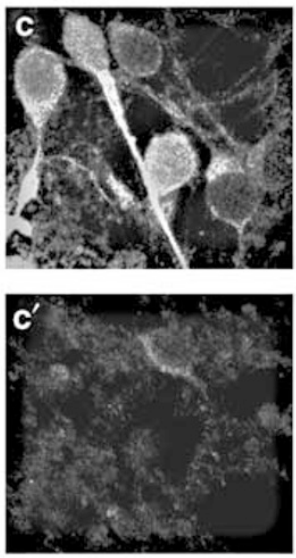

b

Myc-tau (1-44)

IP:9E10

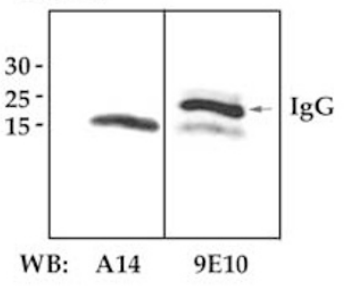

myc-tau (1-44)
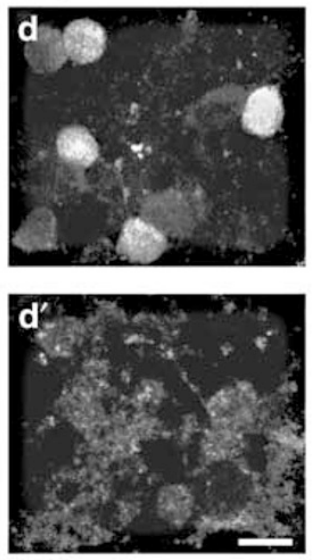

Figure 3 Expression of Ad-myc-tau vectors in cerebellar granule neurons. CGNs were infected at 4 DIV with either Ad-Lac-Z-and Ad-myc-tau-expressing adenovirus vectors at $30 \mathrm{MOI}$ and, $48 \mathrm{~h}$ later, processed for Western blot analysis and immunofluorescence. (a) Western blot analysis on a $10 \%$ SDS-PAGE of lysates from neurons expressing myc-tau (1-441) and myc-tau (1-230) developed with $9 E 10$ (left), an mAb that recognizes the myc epitope tags, and TAU-1 (right), an mAb that recognizes a dephosphorylated epitope in the tau sequence. Arrows in the blot developed with mAb TAU-1 indicate the exogenous tau. (b) Western blot analysis on $15 \%$ SDS-PAGE of immunoprecipitation of tau (1-44) with mAb 9E10 from lysates of tau (1-44)-infected neurons. The immunoprecipitation was performed $24 \mathrm{~h}$ after infection of $2.5 \times 10^{5}$ neurons at $30 \mathrm{MOI}$. (c) Confocal analysis of Ad-Lac-Z (a) and Ad-myc tau (1-441)- (b), Ad-myc tau (1-230)- (c) and Ad-myc tau- (1-44) infected neurons immunostained with $\mathrm{mAb} 9 \mathrm{E} 1048 \mathrm{~h}$ post infection (a-c,) or $12 \mathrm{~h}$ post infection (d), after a combined fixation and permeabilization (a-d) or after extraction and fixation protocol $\left(\mathbf{a}^{\prime}-\mathbf{d}^{\prime}\right)$, as described under 'Materials and Methods'. Notice that while myc-tau (1-441) remains bound to MTs even after detergent treatment $\left(\mathbf{b}^{\prime}\right)$, the myc-tau (1-230) and myc tau (1-44) are completely removed $\left(\mathbf{c}^{\prime}, \mathbf{d}^{\prime}\right)$. Fluorescent images were taken in a laser confocal microscope, as described in the legend of Figure 2. Scale bar: $7 \mu \mathrm{m}$

substantial change in neuronal viability at $96 \mathrm{~h}$ post infection compared to neuronal viability detected at $24 \mathrm{~h}$ post infection (Figure $4 \mathrm{~b}$ ). This finding indicates that the neuronal viability remains unaltered, notwithstanding that the amount of overexpressed tau is maintained constantly elevated (Figure 4c).

Moreover, the expression of exogenous tau proteins (tau 1441 and tau 1-230) in CGNs was not accompanied by an increase in the AD-phosphorylated epitopes on tau - an event that could impair neuronal viability ${ }^{25}$ - as detected with distinct specific antibodies such as AT8, PHF1, and PHF6 (Figure 4d).

\section{Overexpression of tau (1-230) and tau (1-441) blocks apoptosis in cerebellar granule cells}

In a different model of neuronal apoptosis, cell death is accompanied by a depletion of functionally active tau, due to a

Figure 4 Cell viability in myc-tau-infected neurons. CGNs were infected at 4 DIV with either Ad-Lac-Z- or myc-tau-expressing adenovirus vectors at MOI 10, 25, and 50. (a) Neuronal survival was assessed $48 \mathrm{~h}$ later by the MTT assay, and by counting the number of intact nuclei, as reported in Materials and methods. Each data point is the mean \pm S.E. of triplicate determinations of three independent experiments, and is reported as the percentage of uninfected cells (Ctrl), where Ctrl cells have been given a value of 100 ( ${ }^{*} P<0.05$ with respect to Ctrl neurons). (b) Time course of neuronal viability of Ad-myc tau (1-441)-and Ad-myc tau (1-230)-infected neurons at 30 MOI, assessed by the MTT analysis. Data are reported as in (a). (c) Lysates from Ad-myc tau (1-441)-, Ad-myc tau (1-230)- and Ad-Lac-Z-infected neurons were analyzed for protein expression after 24,48 , and $96 \mathrm{~h}$ post infection with mAb $9 \mathrm{E} 10$ and a polyclonal antibody against $\beta$-galactosidase, respectively. Equal loading was confirmed by reacting the membrane with an anti- $\beta$-actin antibody. (d) Western blotting of extracts of Ad-myc tau (1-441)- (top) and Ad-myc tau (1-230)- (bottom) infected neurons with the phosphorylation-dependent antibodies AT8, TAU-1, PHF6, PHF1, and the phosphorylation-independent antibody C17. Notice that in the top portion of (d) only the exogenous overexpressed tau (1-441) is shown, while in the bottom portion the exogenous myc-tau (1-230) (arrow) as well as endogenous tau are shown 
a

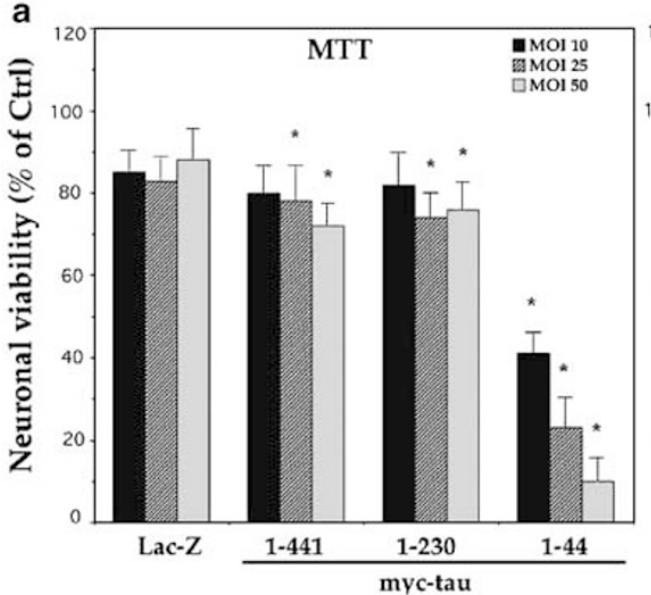

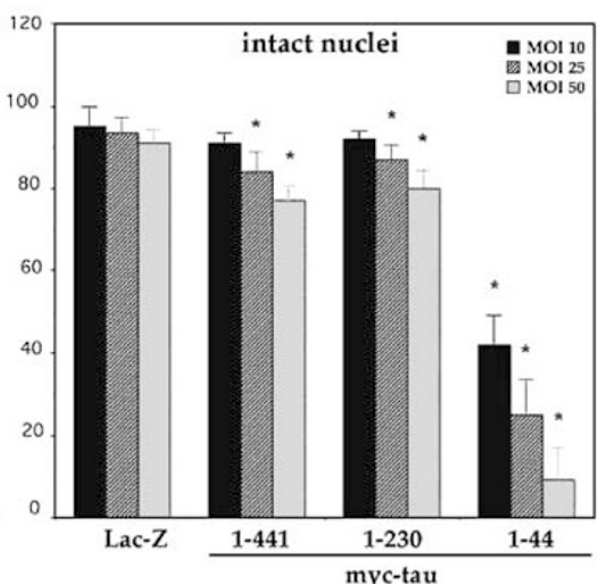

myc-tau

b

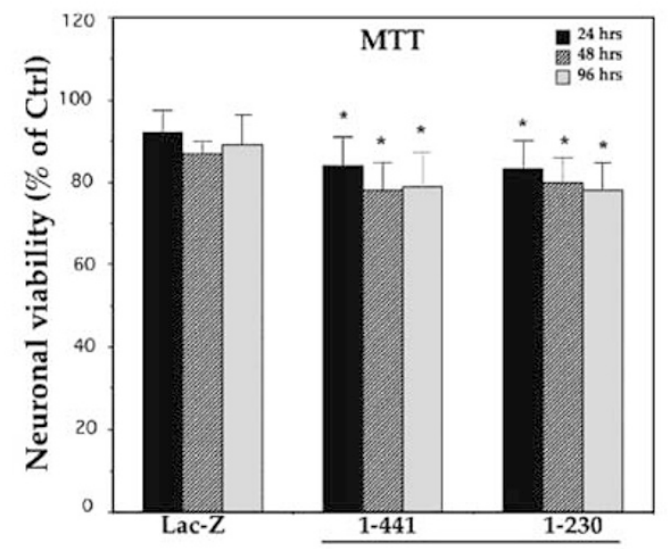

C

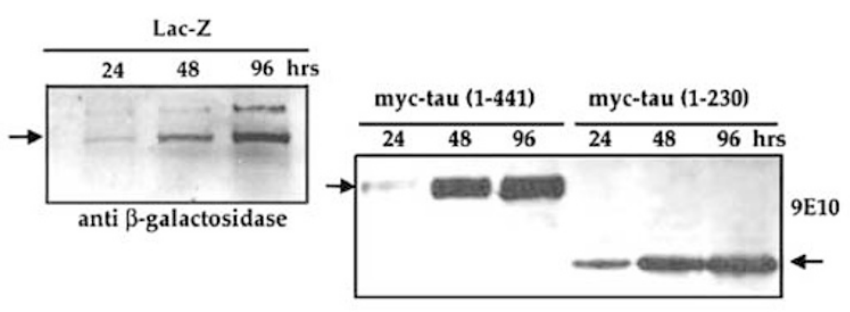

$\beta$ actin

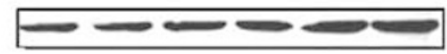

d
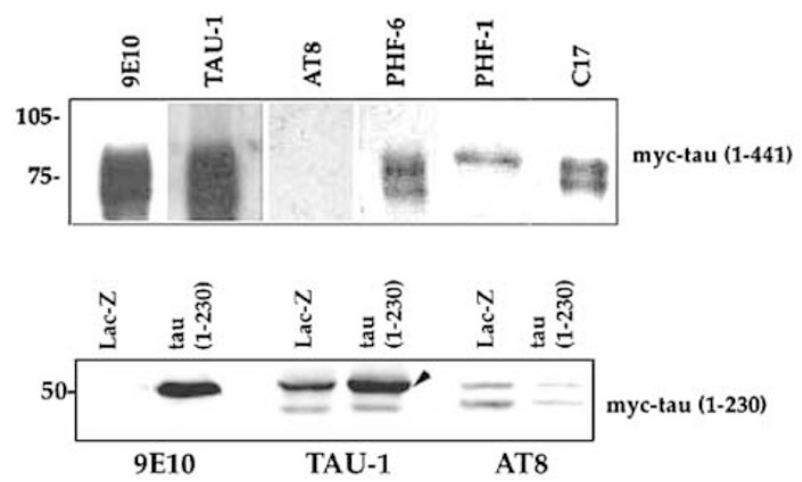
modification of its phosphorylation state as well as proteolytic inactivation. ${ }^{26-29}$

CGNs undergo apoptosis if the potassium concentration is reduced to $5 \mathrm{mM}(\mathrm{K} 5)$, and the serum is removed (S-) after a period of initial growth in 25-30 mM potassium (K25) and
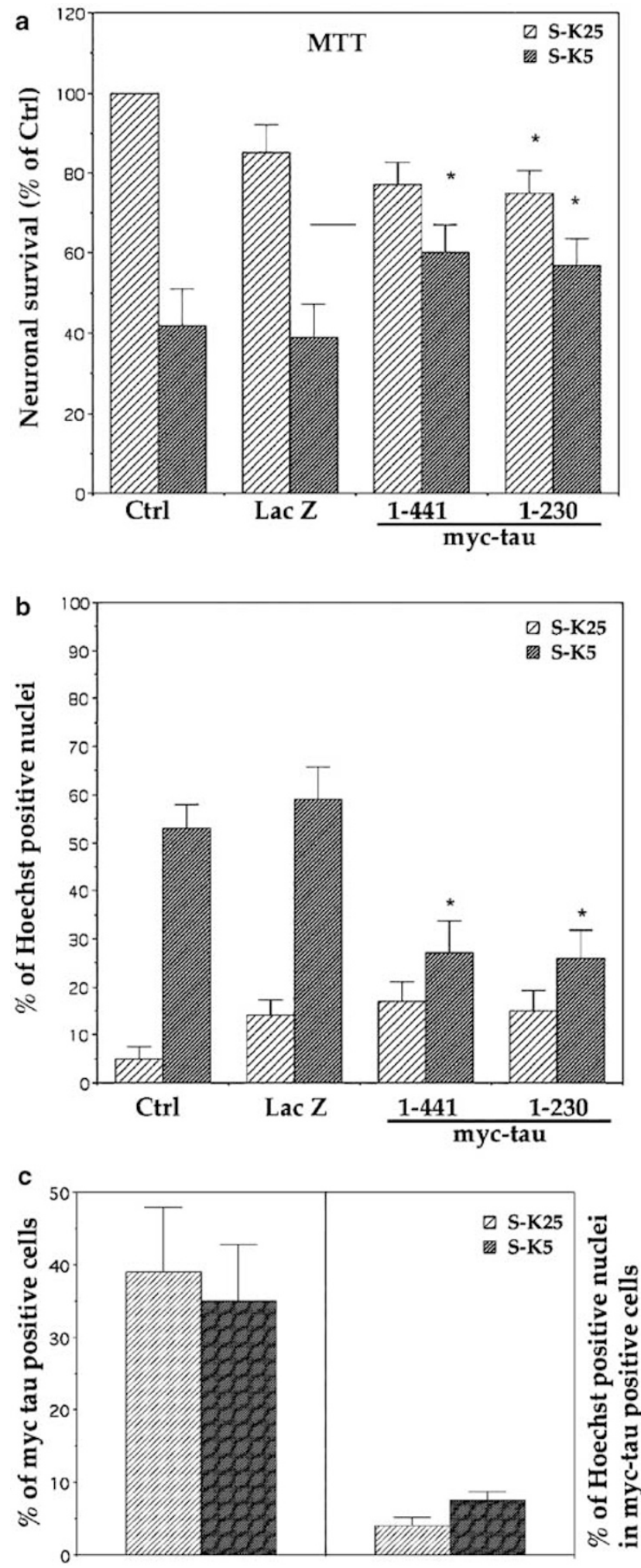

serum $(S+) \cdot{ }^{30-32}$ The viability of cerebellar granule cells is reduced by approximately $50 \% 24 \mathrm{~h}$ after the apoptotic trigger.

As shown in Figure $5 a, b$, the overexpression of tau (1-230) and tau (1-441) inhibited apoptosis, as evaluated by two different parameters, that is, MTT reduction and Hoechstpositive nuclei count (see Materials and methods). Measurements of viability at $24 \mathrm{~h}$ in Lac-Z-infected neurons showed that only $43 \%( \pm 7 \%)$ of granule neurons switched to S-K5 were healthy compared with control neurons switched to SK25. In contrast, tau (1-230)- and tau (1-441)-infected neurons were rescued from apoptotic cell death, with a survival of $74( \pm 8 \%)$ and $76( \pm 5 \%)$, respectively, when compared to sister infected cells maintained in S-K25. It is noteworthy that, as reported previously, only $\sim 60 \%$ of all treated neurons were infected and expressed exogenous tau. Therefore, it was mandatory to assess whether the apoptosisresistant neurons belong to the population of infected or noninfected cells. As shown in Figure $5 \mathrm{c}$, the approximate totality of myc-tau-expressing neurons was not affected by $\mathrm{K}+$ deprivation, that is, they were apoptosis resistant. Moreover, the same neurons were not Hoechst positive.

\section{Tau inhibits the activation of procaspase 3}

In order to elucidate the mechanism of tau-mediated protection against apoptosis, we analyzed the caspase cascade. The execution phase of apoptosis is initiated by the orchestrated action of specific proteases of the caspase family. ${ }^{33}$ Among these, caspase- 3 is mostly involved in the cleavage of apoptotic substrates. ${ }^{34} \mathrm{An}$ increased activity of this protease is a key component of CGN apoptosis after the withdrawal of potassium and serum. ${ }^{35,36}$

We therefore examined the possible involvement of this protein in the regulation of caspase-3 activity, which was assessed by measuring the release of fluorogenic moiety from the peptide substrate in lysates of granule neurons induced to apoptosis. As shown in Figure 6a, the caspase-3-like protease activity both in control uninfected apoptotic neurons as well as in cells overexpressing Lac- $Z$ and undergoing apoptosis was approximately 10 -fold elevated, confirming previous findings. ${ }^{37}$ In contrast, granule neurons overexpressing tau (1-230) and tau (1-441) exhibited a progressively lower level of activation according to the $\mathrm{MOI}$ concentration employed.

Figure 5 Effect of overexpression of tau (1-441) and tau (1-230) on apoptosis by K-deprivation. CGNs were infected at 4 DIV with either Ad Lac-Z or Ad myctau (1-441) and Ad myc-tau (1-230) adenovirus vectors at $30 \mathrm{MOI}$. At 6 DIV, neurons were washed and maintained in a high potassium and serum-free medium (S-K25) or induced in apoptosis by switching the medium to K5 and serum-free BME (S-K5). After $24 \mathrm{~h}$, cell viability was determined (a) by the MTT assay and (b) by counting the number of Hoechst-positive nuclei, as described in Materials and methods. Results are means + S.E. of triplicate determinations of three independent experiments, and are reported as the percentage of Ctrl cells, where Ctrl cells have been given a value of $100\left({ }^{*} P<0.05\right.$ with respect to $\left.\mathrm{Ctrl}\right)$. (c) Histogram showing the number of myc-positive cells in S-K25 and S-K5, and the percentage of Hoechst-positive nuclei (apoptotic nuclei) in myc-tauexpressing neurons in S-K25 and S-K5, respectively. Notice that, as also reported in the text, the totality of myc-tau-expressing neurons does not show signs of nuclear condensation, as documented by Hoechst staining 


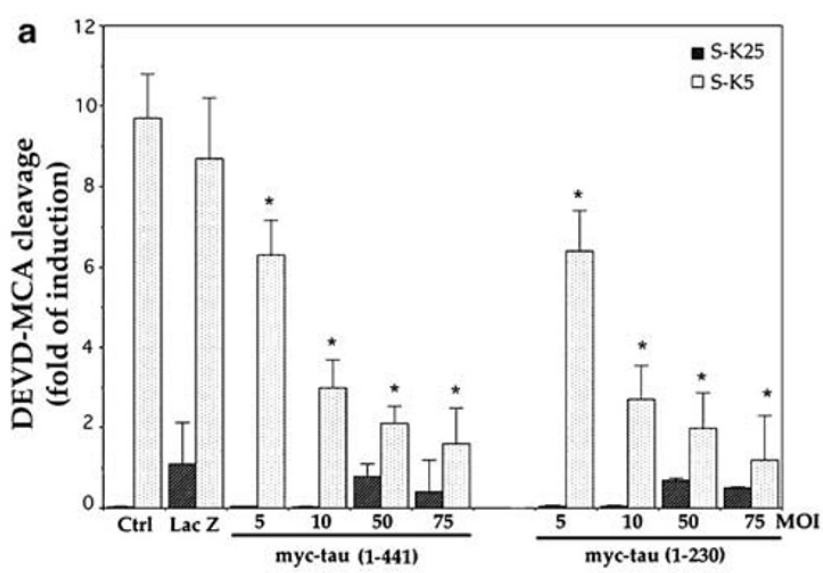

b
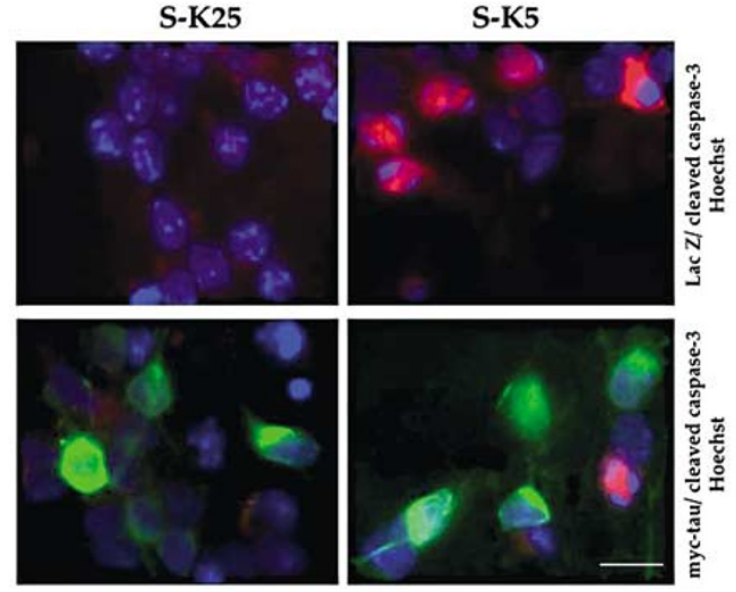

c

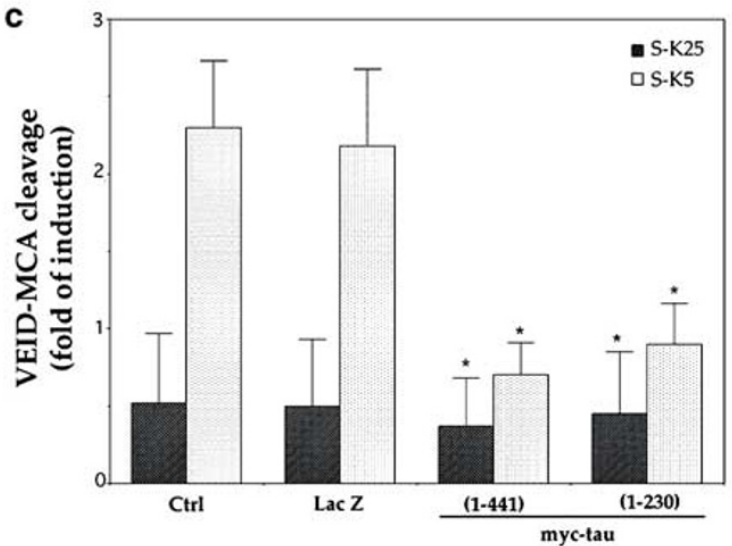

Figure 6 Overexpression of myc-tau largely inhibits caspase-3 activity and procaspase-3 activation in K5-deprived neurons. CGNs were infected at 4 DIV with either Lac Z or myc-tau (1-441) and myc-tau (1-230) adenovirus vectors at different MOI. At 6 DIV, neurons were washed and maintained in a high potassium and serum-free medium (S-K25) or induced in apoptosis by switching the medium to $\mathrm{K} 5$ and serum-free BME (S-K5). (a) After $8 \mathrm{~h}$, neurons were lysed and assayed for DEVD-MCA cleavage (see Materials and methods). (b) Immunofluorescence analysis was performed $6 \mathrm{~h}$ after apoptotic stimulus. Neurons were double immunostained for cleaved caspase-3 (Asp 175) (red) and for myc-tau (green). A representative experiment (of three) is shown. Notice that in all neurons expressing myc-tau, procaspase 3 is not processed. Scale bar: $7 \mu \mathrm{m}$. (c) Caspase-6 activity was measured using the fluorogenic substrate VEID-MCA. The accumulation of MCA was assayed fluorometrically after $30 \mathrm{~min}$ at $37^{\circ} \mathrm{C}$, as reported in Materials and methods. For caspase- 3 and caspase- 6 activities, data - reported as fold of induction - are the means \pm S.E. of triplicate determinations of three independent experiments $\left({ }^{*} P<0.05\right.$ with respect to $\mathrm{Ctrl}$ )
In order to determine whether tau inhibited the activity of caspase-3 protease or prevented its activation, which requires proteolytic processing of the inactive zymogens into activated p17 and p12 subunits, we examined the initial activation of the procaspase-3 in response to the apoptotic trigger. By resorting to an antiserum that specifically recognizes the cleaved, active form of caspase-3, we observed that while cells overexpressing Lac- $Z$ and induced to undergo apoptosis were strongly immunostained, $\sim 100 \%$ of neurons overexpressing tau (1-230) were not immunolabeled, indicating that the procaspase- 3 protein remains uncleaved (Figure 6b). Identical results were obtained in neurons overexpressing tau (1-441) (not shown).

Since it was recently reported that the inhibition of caspase6 activity by CP-VEID-cho prevents caspase-3 activation in granule neurons undergoing apoptosis, ${ }^{38}$ we investigated the modulation of caspase- 6 activity in myc-tau-infected neurons. These neurons displayed a two-fold increase of activity $1 \mathrm{~h}$ after the onset of apoptosis, confirming previous studies, ${ }^{38}$ while caspase- 6 activity was reduced in tau-infected neurons under the same apoptotic conditions (Figure 6c). Taken together, these results strongly suggest that tau suppresses a common upstream step in the pathway leading to the activation of caspase-3-like proteases in response to the apoptotic stimulus, rather than directly inhibiting these proteases.

\section{Neurons overexpressing tau preserve a high level of P-Akt during apoptosis}

Akt is a serine-threonine kinase acting downstream phosphatidylinositol 3-kinase - a lipid membrane-interacting enzyme - in the prosurvival signaling pathway activated by growth factors and depolarization. ${ }^{39}$ The kinase activity of Akt is sustained by phosphorylation on Ser-473 by upstream kinases. This site is rapidly dephosphorylated after the induction of apoptosis by potassium deprivation. ${ }^{40,41}$ As a consequence, a set of Akt substrates is free to exert a proapoptotic action with consequent activation of the caspase cascade. ${ }^{41}$ As reported in Figure $7 \mathrm{a}, \mathrm{b}$, the extent of phosphoAkt, evaluated both by an immunostaining procedure and by Western blotting in neurons expressing tau (1-230) and undergoing apoptosis, was maintained at high levels. On the contrary, in control apoptotic neurons or in neurons infected with Ad-Lac Z, this enzyme was markedly dephosphorylated, suggesting that tau exerts a protective role by supporting high levels of P-Akt, and in this manner controlling the caspasecascade upstream, probably at the plasma-membrane level.

\section{Tau (1-44)-induced cell death is Bcl2 and caspase independent, and is partially prevented by antagonists of NMDA receptors and ROS scavengers}

As shown in Figure 4, tau (1-44) exerted a cytotoxic effect that was concentration dependent and easily detectable by the MTT assay and by counting the number of intact nuclei $48 \mathrm{~h}$ after infection. The maximal neurotoxic effect was reached at $50 \mathrm{MOI}$ as only $10 \%$ of cells were viable at $48 \mathrm{~h}$ post infection. 
Since Bcl2 has been proven to be a key antiapoptotic regulator of neuronal cell death in a variety of in vivo and in vitro paradigms, we examined the response of neurons coexpressing Bcl2 and tau (1-44). It must be pointed out that $\mathrm{Bcl} 2$ is efficiently expressed in $\mathrm{CGNs}$ at $\mathrm{MOI} 30$, and is able to protect cerebellar granules from $\mathrm{KCl}$ deprivation-induced cell a
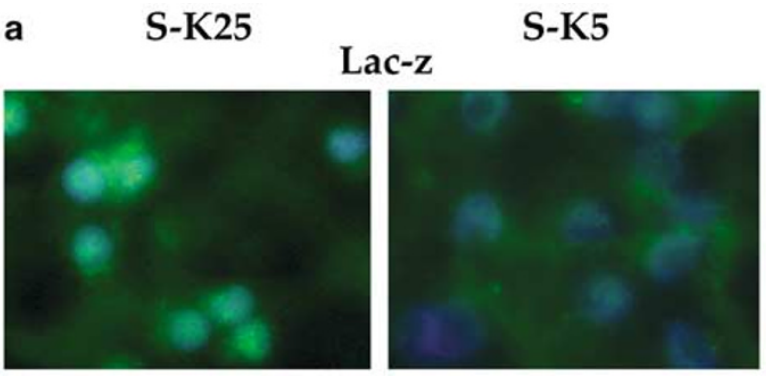

myc-tau
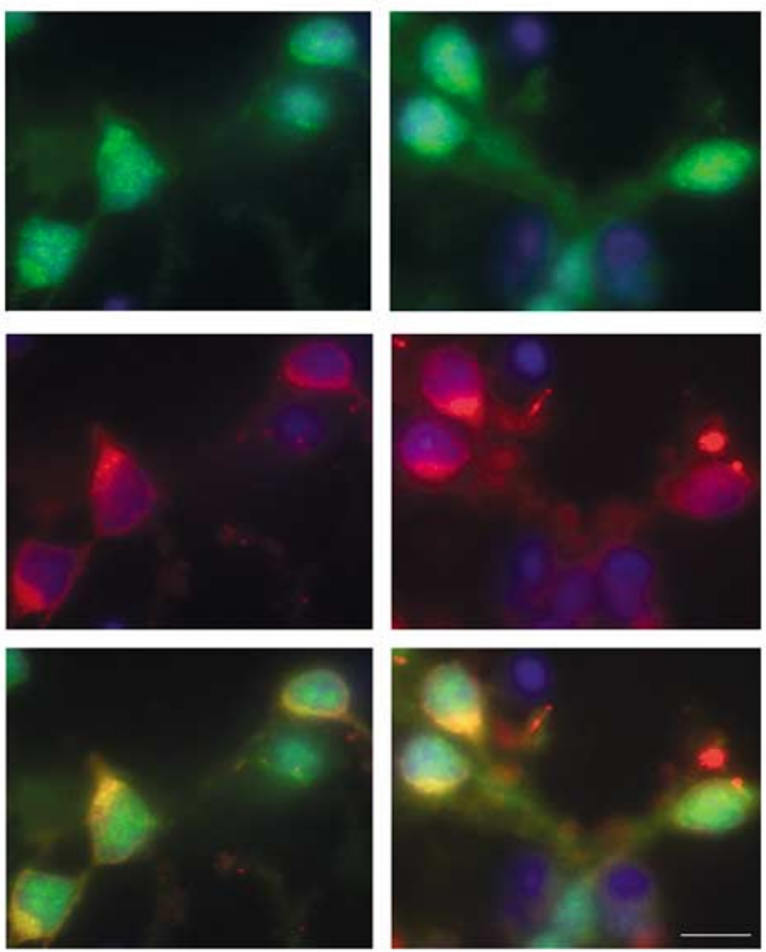

b

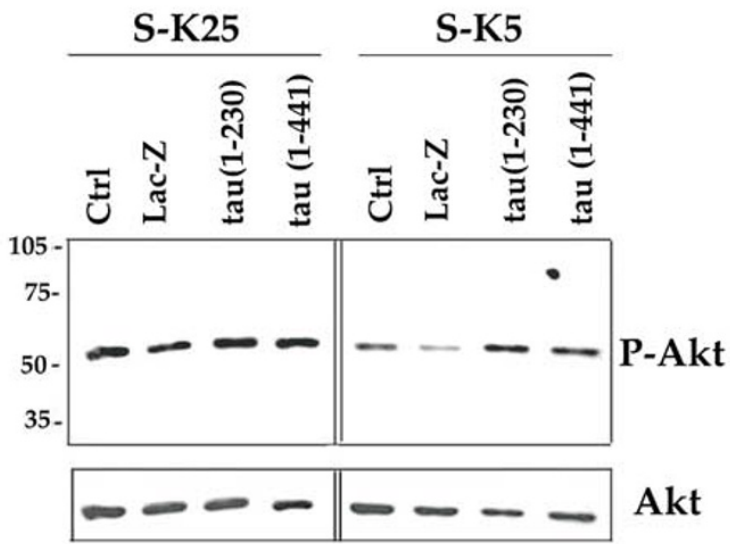

a 范 b

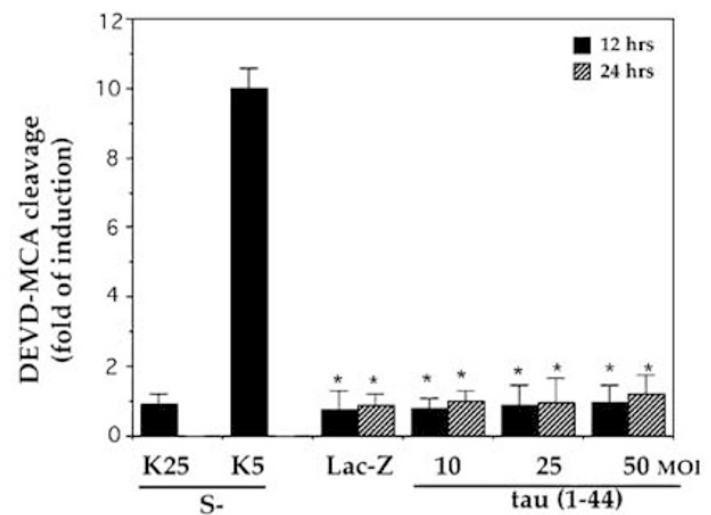

Figure 8 Tau 1-44 cell death is not prevented by inhibitors of apoptosis. (a) CGNs were infected at 4 DIV with either Ad-lacZ- or myc-tau 1-44-expressing adenovirus vectors at $25 \mathrm{MOI}$ in the absence or in the presence of different inhibitors of apoptosis: IGF-1 ( $25 \mathrm{ng} / \mathrm{ml}), \mathrm{z}$-VAD fmk $(100 \mu \mathrm{M})$, and Ad-Bcl2 (30 $\mathrm{MOI}$ ). After $24 \mathrm{~h}$, cell survival was determined by the MTT assay, as described in Materials and methods. Data are reported as percentage of Ctrl cells, where Ctrl cells have been given a value of $100(P<0.1$ with respect to Ctrl cells). (b) Caspase-3 activity in myc-tau- (1-44) infected neurons at different times after infection, determined as reported in Materials and methods; data are reported as the fold of induction $\left({ }^{*} P<0.05\right.$ with respect to $\left.\mathrm{S}-\mathrm{K} 25\right)$

Figure 7 Overexpression of tau preserves high levels of P-Akt during apoptosis. CGNs were infected at 4 DIV with either Lac Z- or myc-tau-(1-441) expressing adenovirus vector at MOI 30. At 6 DIV, neurons were induced to undergo apoptosis, as described in Materials and Methods. After $2 \mathrm{~h}$, (a) neurons were double immunostained for Phospho-Akt (Ser 473) (green) and for myc-tau (red). Nuclei were stained with Hoechst 33258 (blue). A representative experiment (of three) is shown. Scale bar: $7 \mu \mathrm{m}$. (b) Cell lysates were subjected to SDS-PAGE, transferred to polyvinylidene fluoride, and the membranes were probed for active phosphorylated Akt (P-Akt), using an antibody that recognizes Akt phosphorylated on Ser-473. Note that while in Lac-Z-infected neurons the extent of Akt phosphorylation on Ser-473 is markedly reduced in S-K5, in myctau-infected neurons this epitope remains phosphorylated in the same apoptotic condition. The amount of loading was confirmed by reacting the membrane with anti-Akt antibody 

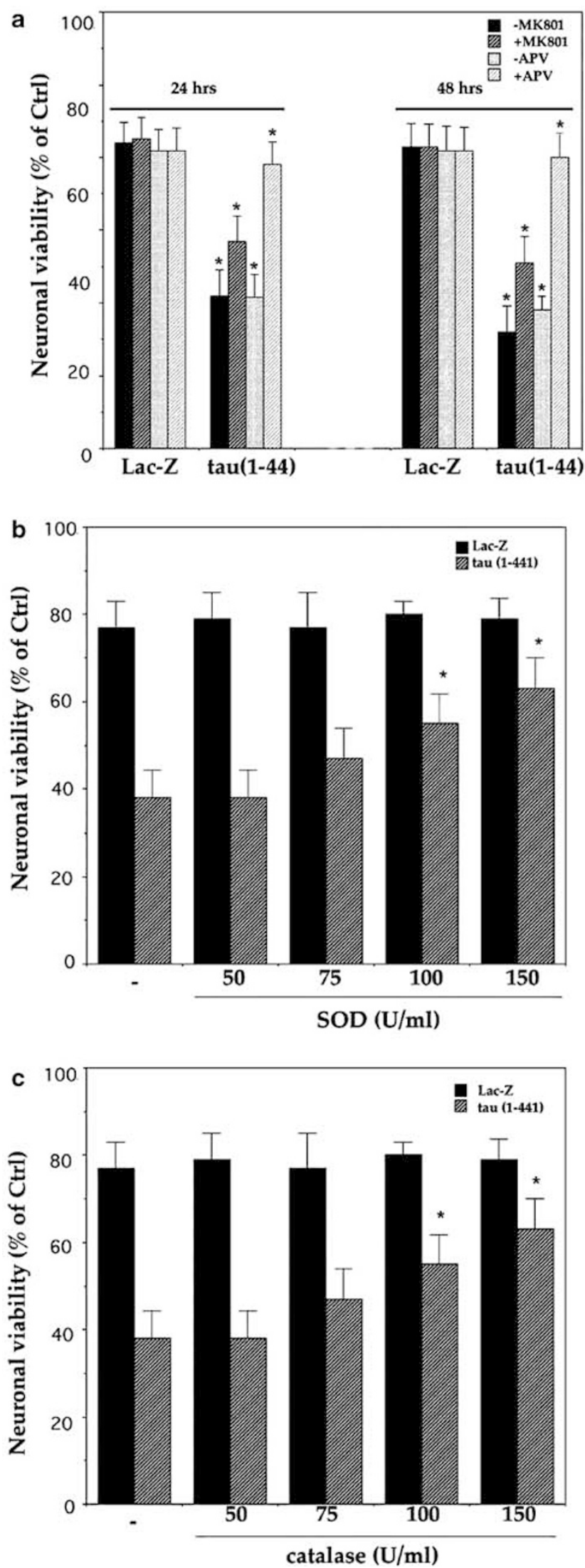

death (Amadoro, unpublished observation). As reported in Figure 8a, neurons cotransfected in this manner underwent death at comparable levels to neurons infected with tau (1-44) alone, suggesting that cell death induced by this $\mathrm{N}$-terminal fragment is $\mathrm{Bcl} 2$ independent and therefore nonapoptotic in origin. This conclusion was further supported by the finding that different inhibitors of CGN apoptosis such as IGF-1 $(25 \mathrm{ng} / \mathrm{ml})$, Forskolin $(10 \mu \mathrm{M}),{ }^{31,32}$ adenosine $(10 \mu \mathrm{M}),{ }^{42}$ and the general inhibitors of caspases, z-VAD-fmk $(100 \mu \mathrm{M})$, added before and after infection failed to rescue tau (1-44)infected neurons from death (Figure 8a). Moreover, no caspase- 3 activity could be detected at different times after infection (Figure 8b) and tau (1-44)-infected neurons acquired a necrotic-like morphology reminiscent of glutamate toxicity (not shown).

Since the glutamate toxicity in these neurons is mediated predominantly by the NMDA receptors, the possible involvement of these receptors in tau (1-44)-induced cell death was investigated. To this aim, tau (1-44)-infected neurons, as well as control cells and Lac Z-infected cells, were treated with NMDA receptor antagonists such as MK801 and APV at different concentrations before and after infection. Neuronal survival was determined by the MTT assay at 12 and $24 \mathrm{~h}$. As reported in Figure 9a, the two NMDA inhibitors were able to protect neurons from tau (1-44)-induced death. The protective effect was more consistent when the NMDA receptors were inhibited $1 \mathrm{~h}$ before the infection, and was more pronounced with APV $(200 \mu \mathrm{M})$, a more specific NMDA antagonist. In fact, the expression of tau (1-44) produced $65 \pm 5.7 \%$ neuronal death $(n=3)$, measured $24 \mathrm{~h}$ later. In the presence of MK801, an APV cell death was reduced to $53 \pm 4.5$ and $30 \pm 3.5 \%$, respectively. It is worth noting that when non-neuronal cells such as COS and MDCK, which are deprived of NMDA receptors, were infected with tau (1-44), no toxic effects were observed (not shown).

Given that reactive oxygen species (ROS) play a central role in glutamate toxicity, ${ }^{43,44}$ experiments were carried out to evaluate the ability of ROS scavengers to protect neurons from tau (1-44)-induced neuronal death.

Neurons were incubated with different concentrations of catalase and SOD after infection with the myc-tau (1-44) adenovirus-expressing vector. As shown in Figure 9b, the two ROS scavengers were able to prevent neuronal death induced by tau (1-44) partially. Thus, the expression of tau (1-44) produced $63 \pm 7.2 \%(n=3)$ neuronal death, measured $24 \mathrm{~h}$ later. In the presence of SOD and catalase added separately, cell death was reduced to $37 \pm 6 \%(n=3)$.
Figure 9 Tau (1-44)- and tau (44-230)-induced cell death is partially prevented by ROS scavengers and by the NMDA antagonist. CGNs were infected at 4 DIV with either Ad-lacZ- or myc-tau 1-44-expressing adenovirus vectors at $25 \mathrm{MOI}$ in the absence or in the presence of NMDA antagonists such as MK801 and APV at the concentrations indicated, or ROS scavengers such as SOD and catalase at different concentrations. After 12 and $24 \mathrm{~h}$, the cell survival was determined by the MTT assay as described in Material and methods. Data are reported as the percentage of $\mathrm{Ctrl}$ or uninfected neurons, where Ctrl cells have been given a value of $100\left({ }^{\star} P<0.05\right.$ with respect to $\mathrm{Ctrl}$ or uninfected neurons) 


\section{Discussion}

Two major findings emerge from the studies reported in this paper, which will be discussed separately: (1) overexpression of the longest human tau isoform, or of its integral N-terminal domain, affords an almost full protection in primary cultures of CGNs against apoptosis; (2) such protection is shifted to a marked toxic effect if only a subdomain of the $\mathrm{N}$-terminal portion is expressed.

Recent studies have demonstrated that overexpression of the longest four repeat isoforms of human tau in animal and fly models is accompanied by neuronal loss. ${ }^{45}$ In these models, death was correlated with the time-dependent overexpression of exogenous tau, and with coincident emergence of phosphorylated and aggregated tau structures ${ }^{22,45,23}$ or, as in the Drosophila model, with the level of expression of the transgene. ${ }^{24}$ We estimated that the expression level of exogenous tau (1-441) and tau (1-230) in CGNs was $\sim$ two-fold the endogenous level of tau (not shown). It should be noted that the level of expression was heterogeneous and varied between individual cells, some of which may express significantly higher amounts of the protein than the immunoblot results indicate. This finding could account for the $\sim 15-$ $20 \%$ death observed in tau (1-441)- and tau (1-230)-infected neurons, a value that is slightly higher than that due to the infection-induced nonspecific cell damage by Lac-Z (Figure 4). It must be pointed out, however, that the rest of the neurons remained viable for several days and expressed constant amounts of the protein, as reported in Figure 4c, indicating that, under our experimental conditions, overexpressed tau or its $\mathrm{N}$-terminal domain is not harmful to neurons. In fact, the overexpression of tau (1-230) as well as full-length tau actually protected CGNs from apoptotic death (Figure 5-7). This finding is apparently in contrast with previous reports regarding the proapoptotic effect of the prolin-rich region within the $\mathrm{N}$-terminal tau domain, ${ }^{16}$ but the different types of cellular models and experimental manipulations may be the basis of such discrepancy. Thus, the proapoptotic action was observed in cyclic non-neuronal cells, while the antiapoptotic effect that we found was in primary cultures of postmitotic neurons. It must be pointed out in this connection that tau is physiologically expressed only in neurons and glial cells. Moreover, the incomplete overlapping of the plasmids used to test the effect of tau on survival may add variances in the interpretation of the different results. In fact, the proapoptotic effect reported by Fasulo et al. ${ }^{16}$ was observed with a region of tau containing P1-P2 and R1, and lacking all the first 151 amino acids (tau (151-274)). In contrast, in our tau (1-230) construct R1 was absent and P2 was deleted from the last 12 aminoacids in which, for example, a functional SH3-binding domain is present. ${ }^{46}$ On the other hand, our reports are in agreement with those of Brandt et al. ${ }^{5}$, demonstrating that the overexpression of the $\mathrm{N}$-terminal domain of the rat tau protein (1-203 and 1-233) is not harmful to PC12 cells.

We found that the overexpression of tau (1-230) and tau (1-441) leads to efficient, dose-dependent inhibition of DEVDspecific caspase, preventing the formation of the active form of caspase 3 (Figure 6a, b), probably upstream of caspase- 6 (Figure 6c). In addition, neurons overexpressing tau and undergoing apoptosis, in which caspase- 3 was inhibited, did not show signs of nuclear condensation or fragmentation when stained with Hoechst (Figure 7b). Moreover, the production of a $17 \mathrm{kDa}$ tau fragment, previously reported as a marker of K-deprived CGNs, ${ }^{13}$ did not occur under this condition, further strengthening the demonstration that the caspase- 3 activity is blocked in myc-tau-infected neurons (data not shown).

Depolarization, like neurotrophins, promotes neuronal survival by keeping the caspase cascade silent, and by activating different signaling pathways like those involving the MAP kinase and/or the phosphatidylinositol-3-kinase (PI-3kinase). Since MAP kinase activation is not required for potassium-mediated survival ${ }^{41}$ while downregulation of $\mathrm{PI}$ 3kinase pathway occurs during potassium-deprivation-induced cell death, ${ }^{47}$ we studied the effect of myc-tau overexpression on the Akt/protein kinase B serin/threonin kinase, a downstream target of $\mathrm{Pl}-3$ kinase. ${ }^{48} \mathrm{We}$ found that in neurons expressing tau and undergoing apoptosis, the extent of phosphoAkt was maintained at control levels, while, as also previously surmised, in control apoptotic neurons, or in neurons infected with Lac-Z, it was markedly reduced (Figure $7 a, b)$.

This finding hints that the apoptosis-inhibitory effect of tau did not probably involve a strong interaction of tau with the MT network, as also supported by the observation that tau (1230), which has a weak MT interaction site, exerted an analogous protective effect against the apoptotic stimulus. Therefore, it is possible that a crosstalk between tau and the neuronal plasma membrane is required to maintain high levels of Akt during apoptosis.

The activation of Akt is likely to be accompanied by a decrease in glycogen synthase kinase-3 $\beta$ (GSK3 $\beta$ ) activity, a major tau kinase ${ }^{49}$ as suggested by the observation that phosphorylation at Ser 202-205 (evaluated by mAb AT8) on tau sequence, both in the endogenous and exogenous tau, did not increase in the presence of overexpressed tau (1-230) as well (see Figure 4d).

Akt activation could be achieved by: (1) direct stimulation of PI3-kinase activity; (2) activation of other kinases able to phosphorylate Akt; (3) interference with the metabolism of phosphoinositides, thus regulating the activity of PI-3kinase; (4) inhibition of phosphatases acting on Akt, either directly or indirectly. While the first hypothesis is invalidated by previous studies $^{50}$ regarding the inability of tau, unlike gelsolin, to activate PI3-kinase, the second and third hypotheses could be linked together by an involvement of PLC- $\gamma$, a protein that directly, or indirectly through PIP2, is activated by tau. ${ }^{6,7}$ Further experiments are necessary to establish the correct hypothesis and evaluate a possible functional link between tau overexpression and the activation of PLC- $\gamma$ in CGNs.

In this connection, it has been reported that tau interacts with neuronal plasma membrane components through the amino-terminal projection domain, ${ }^{5}$ and that this interaction is impaired by phosphorylation at sites that are altered in PHF, such as those recognized by mAb AT8, PHF-1, and PHF-6. ${ }^{51}$ It must pointed out that none of the sites cited above underwent hyperphosphorylation in CGNs overexpressing tau (1-230) or tau (1-441) (Figure 4d), suggesting that these peptides could affect the neuronal functions by interacting with some cytoplasmic membrane components. Whether 
such an action is exerted via competition with the internal pool of tau at the membrane level, as suggested by Brandt's finding ${ }^{5}$ or via other mechanisms, remains to be elucidated.

As far as tau (1-44) overexpression is concerned, the question is if this effect is to be considered as a gain of function, or alternatively, if tau (1-44) overexpression somewhat interferes with the function of the internal pool of tau. This latter hypothesis could be sustained by the observation that tau is able to acquire a loop-shaped conformation by the interaction between the $\mathrm{N}$-terminal end and the first and second MT-binding domains. ${ }^{52,53}$ Whatever the mechanism, an involvement of NMDA receptors is likely to be the mode by which this $\mathrm{N}$-terminal subdomain of the tau protein leads CGNs to death (Figures 8, 9a, b). This conclusion was corroborated by the evidence that different inhibitors of CGN apoptosis (IGF-1, overexpression of Bcl2 and forskolin) failed to prevent tau (1-44)-induced cell death, and by the findings that neuronal viability was recovered by the antagonist of NMDA receptors and of ROS scavengers (SOD and catalase). However, the precise mechanism through which tau (1-44) promotes glutamate-mediated excitotoxicity remains to be elucidated. The activation of NMDA receptors could occur via excessive glutamate release from cellular stores in tau-infected neurons due to an increase in intracellular calcium concentration. Alternatively, tau (1-44) expression may increase NMDA receptor permeability or sensitivity, rendering neurons more vulnerable to the normal concentration of glutamate constantly released in the culture medium. The finding that non-neuronal cells such as COS and MDCK, which are devoid of NMDA receptors, are not susceptible to the toxic action of tau (1-44) (not shown) further strengthens the active, crucial role of NMDA receptors.

The findings presented in this paper clearly indicate that inappropriate proteolysis of tau, as that occurring during in vitro neuronal apoptosis and in $A D$, may generate a toxic fragment which, in turn, could exacerbate and propagate the death process. In this regard, it must be pointed out that the $\mathrm{N}$ terminal cleavage of the tau protein by caspase is an early event in AD, which may precede and lead to the formation of NTF. ${ }^{18}$

In conclusion, the findings reported in this paper reveal a hitherto unrecognized role of tau, which is exerted at the plasma membrane level and involves an interplay with the antiapoptotic pathway(s). Future studies should assess whether such a role is exerted by the 'physiological' intracellular tau pool, thus broadening the number of functions of this protein, and whether under certain pathological conditions a short $\mathrm{N}$-terminal fragment is generated along with the toxic effects reported in this study.

\section{Materials and Methods}

Ac-DEVD-MCA and Ac VEID-MCA was obtained from Biomol (Plymouth Meeting, PA, USA). Rabbit anticleaved caspase-3 (Asp 175) and rabbit antiphospho-Akt (Ser 473) IHC specific were obtained from Cell signaling Technology (New England Biolabs Ltd.). Rabbit anti- $\beta$-galactosidase was obtained from Chemicon International. Inc. Rabbit anti-Akt was obtained from Santa Cruz Biotechnology (Santa Cruz, CA, USA). Mouse anti $\beta$ actin was obtained from Sigma.
The following antibodies antitau were used in this study: C17 a goat polyclonal antibody that recognizes the $\mathrm{C}$-terminal of the tau protein, a phosphorylation-independent antibody purchased from Santa Cruz Biotechnology (Santa Cruz, CA, USA). mAb TAU-1 was obtained from Boehringer Mannheim (Mannheim, Germany); mAb PHF- ${ }^{54}$ mAb PHF$6^{55}$ and $\mathrm{mAb} A T 8^{56}$ - kindly provided by Dr V Lee (Department of Pathology and Laboratory Medicine, University of Pennsylvania School of Medicine, Philadelphia, PA, USA) - are phosphorylation-dependent antibodies. The sites recognized by all these antitau antibodies are reported in Figure 1. Mouse (9E10) and rabbit (A14) antibodies against the myc epitope were obtained from Santa Cruz Biotechnology. Superoxide dismutase (EC 1.15.1.1), catalase (EC 1.11.1.6), and (+)-MK-801 hydrogen maleate were obtained from Sigma.

\section{Construction and purification of recombinant adenoviral vectors}

Plasmids encoding the full-length or deleted tau cDNA were generated by PCR amplifications using the tau40pSG5 vector as a template. ${ }^{15}$ The numbering of tau fragment is according to the longest human tau isoform tau 40.

The $5^{\prime}$-primer for tau (1-441), tau (1-230), and tau (1-44) was $5^{\prime}$ AGCTGAATTCAATGGCTGAGCCCCGCCAG-3', while the $3^{\prime}$-primers were: 5'-GACCGCTCGAGTCACAAACCCTGCTTGGC-3', 5'-GACCGCTCGAGTCAACGGACCACTGCCAC-3, and 5'-GACCGCTCGAGTCACAGGCCAGCGTCCGTGTC-3', respectively.

PCR primers contained EcoRI $\left(5^{\prime}\right)$ and Xhol $\left(3^{\prime}\right)$ for insertion into EcoRl-Xhol-cut pCS2 + MT downstream the 6 myc epitope tags. ${ }^{57}$

Replicant-deficient Ad5 adenoviral vectors, encoding human full-length or truncated tau proteins, were prepared using the Adeno-X Expression System provided by Clontech (Palo Alto, CA, USA).

In brief, the assembly and production of recombinant adenovirus were obtained in three phases. Human tau cDNA cassettes were subcloned into the pShuttle vector (Xbal blunt-Kpnl) after digestion (BamHI blunt-Kpnl) from pCS2 + MT for E. coli propagation. Next, the excised expressioncassettes were transferred to Adeno-X Viral DNA by in vitro ligation reaction. Finally, the new tailored recombinant adenoviral plasmids were packaged into infectious particles by lipofectamine-transfecting human embryonic kidney (HEK) 293 cells. The medium was replaced with a growth medium containing $0.6 \%$ Noble Agar $4 \mathrm{~h}$ after transfection. Isolated plaques were harvested, and viral vectors were amplified on fresh plates of 293 cells. The high titer viral vectors $\left(2 \times 10^{8}\right)$ were harvested from cell lysates and used directly. Alternatively, purification on $\mathrm{CsCl}$ gradients was performed. ${ }^{58,59}$ The determination of the infectious titer was performed by plaque assay on HEK 293 cells. Vector stocks were stored at $-70^{\circ} \mathrm{C}$ until needed.

Adenovirus-expressing $\beta$-galactosidase (Ad-Lac Z) and Bcl2 (Ad-Bcl2) were provided by Dr Marco Crescenzi (Laboratorio di Tossicologia Comparata ed Ecotossicologia, Istituto Superiore di Sanità, Roma).

\section{Neuronal cultures}

Cultures enriched in granule neurons were obtained from dissociated cerebella of 8-day-old Wistar rats (Charles River, Calco, Italy), as previously described. ${ }^{60}$ Cells were plated in basal medium Eagle (BME; Life Technologies, Gaithersburg, MD, USA) supplemented with $10 \%$ fetal bovine serum, $25 \mathrm{mM} \mathrm{KCl}$, and $2 \mathrm{mM}$ glutamine (Life Technologies) on dishes (Nunc, Roskilde, Denmark) coated with poly-L-lysine. Cells were plated at $2.5 \times 10^{6}$ per $35 \mathrm{~mm}$ dish or $7 \times 10^{6}$ per $60 \mathrm{~mm}$ dish. $1 \beta$ - 
Arabinofuranosylcytosine $(10 \mu \mathrm{M})$ was added to the culture medium 18$22 \mathrm{~h}$ after plating to prevent the proliferation of non-neuronal cells.

\section{Infection of neurons}

For infection of cerebellar granule neurons (CGNs), 4-day-old cultures were used. The volume of the medium was reduced to one-third and the recombinant adenovirus was added at an indicated $\mathrm{MOI}$. After allowing the virus to adsorb for $1 \mathrm{~h}$, the medium was rendered back to its original volume. Neurons were further cultured up to 6 DIV when the experiments were performed.

\section{Induction of apoptosis}

Apoptosis was induced as previously reported. ${ }^{29}$ Cultures (6 DIV) were washed two times and maintained in serum-free BME $(5 \mathrm{mM} \mathrm{KCl})$ supplemented with glutamine and gentamicin. Control cells were washed and maintained in a serum-free medium containing $25 \mathrm{mM} \mathrm{KCl}$.

\section{Assessment of neuronal viability}

Viable CGNs were quantified by counting the number of intact nuclei, after lysing the cells in a detergent-containing solution ${ }^{61,62}$ and by the MTT tetrazolium salt assay. ${ }^{63}$ Briefly, the MTT tetrazolium salt $(0.25 \mathrm{mg} / \mathrm{ml})$ was added to neurons grown in 24-well plates and incubated for $1-2 \mathrm{~h}$ at $37^{\circ} \mathrm{C}$. The reaction media were then gently aspirated, and isopropanol containing $0.08 \mathrm{~N} \mathrm{HCl}$ was added to solubilize the formazan product. Formazan-isopropanol mixtures were then transferred to 96-well plates and quantified using the Multiskan plate reader at $570 \mathrm{~nm}$ (Labsystem Multiskan MCC/340).

\section{Immunofluorescence}

For immunostaining of myc-tau, 2 days after infection, CGNs were fixed using a combined fixation and extraction protocol ${ }^{64,65}(0.3 \%$ glutaraldehyde, $0.5 \% \mathrm{NP} 40,80 \mathrm{mM}$ PIPES/KOH, pH 6.8, $5 \mathrm{mM}$ EGTA, and $1 \mathrm{mM}$ $\mathrm{MgCl}_{2}$ ) at $37^{\circ} \mathrm{C}$ for $10 \mathrm{~min}$. After treatment with $\mathrm{NaBH}_{4}$ and blocking with $5 \%$ goat serum, the cells were incubated with the mAb 9E10 antibody $(1: 200$, Santa Cruz) at room temperature (RT) for $1 \mathrm{~h}$. Neurons were then washed and incubated with TRITC-conjugated secondary antibodies goat antimouse ( 1 : 400 Sigma, St. Louis, MO, USA) at RT for $1 \mathrm{~h}$. For the extraction of noncytoskeletal-associated tau, neurons were rinsed with PBS, treated with $0.1 \%$ Triton X-100 in the extraction buffer ( $80 \mathrm{mM}$ PIPES/KOH pH 6.8, $1 \mathrm{mM} \mathrm{MgCl} 2,1 \mathrm{mM} \mathrm{EGTA}, 30 \%$ glycerol, $1 \mathrm{mM} \mathrm{GTP}$ ) for $30 \mathrm{~s}$, and then fixed with glutaraldehyde $(0.3 \%$ glutaraldehyde, $80 \mathrm{mM} \mathrm{PIPES} / \mathrm{KOH}, \mathrm{pH} 6.8$, $5 \mathrm{mM} \mathrm{EGTA}$, and $1 \mathrm{mM} \mathrm{MgCl}_{2}$ ) after rinsing with an extraction buffer and PBS. All treatments were carried out at $37^{\circ} \mathrm{C}$. MDCK cell lines were double immunostained with mouse antitubulin ( $1: 2000$ Sigma, St. Louis, MO, USA) and with rabbit anti-myc antibody (1:200 Santa Cruz) for $1 \mathrm{~h}$ at $\mathrm{RT}$, rinsed twice in PBS $1 \times$, and stained with FITC- or TRITC-conjugated secondary antibody (Sigma, St. Louis, MO, USA) for $30 \mathrm{~min}$. Fluorescences were analyzed by confocal fluorescence microscopy.

For immunostaining of cleaved caspase-3 and P-Akt on tau-infected neurons, GCNs were fixed with $4 \%$ (w/v in PBS $1 \times$ ) paraformaldehyde for $15 \mathrm{~min}$ at RT. The fixed cells were washed in PBS $1 \times \mathrm{pH} 7.5$ and then permeabilized with $0.2 \%$ Triton $\mathrm{X}-100-0.1 \mathrm{M}$ Tris- $\mathrm{HCl} \mathrm{pH} 7.4$ for $5 \mathrm{~min}$. The coverslips were saturated with $3 \%$ normal goat serum in PBS $1 \times$ for $3 \mathrm{~h}$, and were then incubated with rabbit anticleaved caspase-3 (diluted $1: 50$ ) overnight at $4^{\circ} \mathrm{C}$ or with rabbit antiphospho-Akt (diluted $1: 100$ ). Another incubation was performed for an additional hour with $9 \mathrm{E} 10-\mathrm{a}$ mouse anti-Myc antibody(diluted 1:100) - rinsed twice in PBS $1 \times$ and stained with FITC- or TRITC-conjugated secondary antibody (Sigma, St. Louis, MO, USA) for $30 \mathrm{~min}$. The nuclei were stained with Hoechst 33258 (Sigma, St. Louis, MO, USA) $0.5 \mathrm{mg} / \mathrm{ml}$ in PBS for $5 \mathrm{~min}$.

\section{Western blot analysis}

The total proteins were extracted by scraping the cells in an SDS-reducing sample buffer and then by boiling for $5 \mathrm{~min}$. Equal amounts of protein were subjected to SDS-PAGE on $7.5-15 \%$ linear gradient or $10 \%$ gels. ${ }^{66}$ After electroblotting onto a nitrocellulose membrane (Hybond-C), proteins were visualized using appropriate primary antibodies. All primary antibodies were diluted in $0.5 \%(\mathrm{w} / \mathrm{v})$ nonfat dry milk, and incubated with the nitrocellulose blot overnight at $4{ }^{\circ} \mathrm{C}$. Incubation with secondary peroxidasecoupled anti-mouse was performed by using the ECL system (Amersham, Arlington Heights, IL, USA).

\section{Immunoprecipitation of myc-tau (1-44)}

Tau (1-44)-infected neurons were rinsed three times with ice-cold PBS, and lysed on plates at $0^{\circ} \mathrm{C}$ for $20 \mathrm{~min}$ in $500 \mu \mathrm{IIP}$ buffer $(50 \mathrm{mM}$ Tris, $\mathrm{pH}$ 8.0, $150 \mathrm{mM} \mathrm{NaCl}, 10 \%$ glycerol, $0.5 \mathrm{mM}$ EDTA, $0.5 \mathrm{mM}$ EGTA, $50 \mathrm{mM}$ $\mathrm{NaF}, 1 \mathrm{mM} \mathrm{NaOV}, 1 \% \mathrm{NP} 40$ ) supplemented with protease inhibitor cocktail (Sigma). Lysates were centrifuged at $4{ }^{\circ} \mathrm{C}$ for $10 \mathrm{~min}$ at $3000 \mathrm{rpm}$, and the supernatants were precleared using $20 \mu \mathrm{l}$ of protein $\mathrm{A} /$ protein $\mathrm{G}$ beads (Boerhinger) for $1 \mathrm{~h}$ at $4^{\circ} \mathrm{C}$. The precleared protein extracts were immunoprecipitated by standard procedures using mAb $9 \mathrm{E} 10$.

\section{Fluorogenic peptide substrate assay for caspase activities}

Caspase-3 activity was measured, as previously described, ${ }^{38}$ after $8 \mathrm{~h}$ in S-K5; 500000 granule cells were washed once with PBS $1 \times$ and lysed in $100 \mu$ of buffer A ( $10 \mathrm{mM} \mathrm{HEPES} \mathrm{pH} \mathrm{7.4,} 42 \mathrm{mM} \mathrm{KCl,} 5 \mathrm{mM} \mathrm{MgCl}$, $1 \mathrm{mM}$ DTT, and $1 \mathrm{mM}$ PMSF, 0.5\% 3-[(3-cholamidopropyl) dimethylammonio]-1propanesulfonic acid (CHAPS), and $1 \mathrm{mg} / \mathrm{ml}$ leupeptin). The lysate $(25 \mu \mathrm{l})$ was combined with $75 \mu$ of buffer B (25 mM HEPES, $1 \mathrm{mM}$ EDTA, $0.1 \%$ CHAPS, $10 \%$ sucrose, and $3 \mathrm{mM}$ DTT pH 7.5) containing $30 \mu \mathrm{M} \mathrm{Ac-}$ DEVD-MCA, and incubated for $20 \mathrm{~min}$ at RT. Caspase- 6 activity was measured, as previously described, ${ }^{39}$ combining $40 \mu$ of lysate from buffer A with $200 \mu$ l of buffer B ( $25 \mathrm{mM}$ HEPES-KOH pH 7.5, $50 \mathrm{mM} \mathrm{NaCl}, 1 \mathrm{mM}$ EDTA, $5 \mathrm{mM}$ EGTA, $2 \mathrm{mM} \mathrm{MgCl} 2,0.1 \%$ CHAPS, $10 \%$ sucrose, and $10 \mathrm{mM}$ DTT) containing $20 \mu \mathrm{M}$ of the caspase- 6 fluorogenic substrate AcVEID-MCA, and incubated at $37^{\circ} \mathrm{C}$ for $30 \mathrm{~min}$. The fluorescence was measured at an excitation of $380 \mathrm{~nm}$ and an emission of $460 \mathrm{~nm}$ wavelength, using a Packard Fluorocount microplate reader (Packard Bioscience Company).

\section{Statistical analysis}

All experiments were carried out in triplicates and repeated at least three times. Data were expressed as means \pm S.E. $(n=3)$. Statistical significance was analyzed by Student's test (Statview 4.01). $P$-values are ${ }^{\star} P<0.05 ;{ }^{*} P<0.01 ;{ }^{* \star} P<0.001$.

\section{Acknowledgements}

This study was supported by the Ministero della Sanità Grant ICS 110.1/ RA00.54 to NC, Progetto Strategico sulla Malattia di Alzheimer del 
Ministero della Sanità and Telethon grant n E0855 to PC. We thank Dr Andrew Bradbury, Dr Marco Venanzoni, and Dr Andrea Levi for comments on this manuscript. We are grateful to $\mathrm{V}$ Lee for the generous gift of $\mathrm{mAb}$ AT8, PHF6, PHF1.

\section{References}

1. Goedert M, Spillantini MG, Jakes R, Rutherford D and Crowther RA (1989) Multiple isoforms of human microtubule-associated protein tau: sequences and localization in neurofibrillary tangles of Alzheimer's disease. Neuron 3: 519526

2. Himmler A, Drechsel D, Kirschner MW and Martin Jr DW (1989) Tau consists of a set of proteins with repeated C-terminal microtubule binding domains and variable N-terminal domains. Mol. Cell. Biol. 9: 1381-1388

3. Goedert M, Crowther RA and Garner CC (1991) Molecular characterization of microtubule-associated proteins tau and MAP2. Trends Neurosci. 14: 193-199

4. Hirokawa N (1994) Microtubule organization and dynamics dependent on microtubule-associated proteins. Curr. Opin. Cell Biol. 6: 74-81

5. Brandt R, Leger J and Lee G (1995) Interaction of tau with the neural plasma membrane mediated by tau's amino-terminal projection domain. J. Cell Biol. 131: $1327-1340$

6. Hwang SC, Deok-Young J, Yun Soo B, Hynshik Kim J and Rhee SG (1996) Activation of phospholipase $\mathrm{C}-\gamma$ by the concerted action of tau proteins and arachidonic acid. J. Biol. Chem. 271: 18342-18349

7. Scott MJ and Johnson GVW (1998) Tau complexes with phospholipase C- $\gamma$ in situ. NeuroReport 9: 67-71

8. Lee G, Newman ST, Gard DL, Band H and Panchamoorthy G (1998) Tau interacts with src-family non-receptor tyrosine kinases. J. Cell Sci. 111: 31673177

9. Flanagan LA, Cunningham CC, Chen J, Prestwich GD, Kosik KS and Janmey PA (1997) The structure of divalent cation-induced aggregates of PIP2 and their alteration by gelsolin and tau. Biophys. J. 73: 1440-1447

10. Lovestone S and Reynolds CH (1997) The phosphorylation of tau: a critica stage in neurodevelopment and neurodegenerative processes. Neuroscience 78: 309-324

11. Grundke-Iqbal I, Iqbal K, Tung YC, Quinlan M, Wisniewski HM and Binder LI (1986a) Abnormal phosphorylation of the microtubule-associated protein tau in Alzheimer cytoskeletal pathology. Proc. Natl. Acad. Sci. USA 83: 4913-4917

12. Wang JZ, Grundke-Iqbal I and lqbal K (1996) Glycosylation of microtubuleassociated protein tau: an abnormal posttranslational modification in Alzheimer's disease. Nat. Med. 8: 871-875

13. Ledesma MD, Bonay P, Colaco C and Avila J (1994) Analysis of microtubuleassociated protein tau glycation in paired helical filaments. J. Biol. Chem. 269: 21614-21619

14. Novak M, Kabat J and Wischick CM (1993) Molecular characterization of the minimal protease resistant tau unit of Alzheimer's disease paired helical filament. EMBO J. 12: 365-370

15. Canu N, Dus L, Barbato C, Ciotti MT, Brancolini C, Rinaldi AM, Novak M, Cattaneo A, Bradbury A and Calissano P (1998) Tau cleavage and dephosphorylation in cerebellar granule neurons undergoing apoptosis. J. Neurosci. 18: 7061-7074

16. Fasulo L, Ugolini G, Visentin M, Bradbury A, Brancolini C, Verzillo V, Novak M and Cattaneo A (2000) The neuronal microtubule-associated protein tau is substrate of caspase-3 and an effector of apoptosis. J. Neurochem. 75: 624633

17. Chung CW, Song YH, Kim IK, Yoon WJ, Ryu BR, Jo DG, Woo HN, Kwon YK, Kim HH, Gwag BJ, Mook-Jung IH and Jung YK (2001) Proapoptotic effects of tau cleavage product generated by caspase-3. Neurobiol. Dis. 8: 162-172

18. Rohn TT, Rissman RA, Davis MC, Kim YE, Cotman CW and Head E (2002) Caspase-9 activation and caspase cleavage of tau in the Alzheimer's disease brain. Neurobiol. Dis. 11: 341-354

19. Brandt R and Lee $G$ (1993) Functional organization of microtubule associated protein tau. Identification of regions which affect microtubular growth nucleation, and bundle formation in vitro. J. Biol. Chem. 268: 3414-3419

20. Leger JG, Brandt R and Lee $G$ (1994) Identification of tau region required for process formation in PC12 cells. J. Cell Sci. 102: 227-237
21. Kaech S, Ludin B and Matus A (1996) Cytoskeletal plasticity in cells expressing neuronal microtubule-associated proteins. Neuron 17: 1189-1199

22. Hall GF, Yao J and Lee G (1997) Tau overexpressed in identified lamprey neurons in situ is spatially segregated by phosphorylated state, forms hyperphosphorylated, dense aggregation and induce neurodegeneration. Proc. Natl. Acad. Sci. USA 94: 4733-4738

23. Hall GF, Lee VMY, Lee G and Yao J (2001) Staging of neurofibrillary degeneration caused by human tau overexpression in a unique cellular model of human tauopathy. Am. J. Pathol. 158: 235-246

24. Jackson GR, Wiedau-Pazos M, Sang TK, Wagle N, Brown CA, Massachi S and Geschwind DH (2002) Human wild-type tau interact with wingless pathway components and produces neurofibrillary pathology in Drosophila. Neuron 34: $509-519$

25. Fath $\mathrm{T}$, Eidenmuller $\mathrm{J}$ and Brandt $\mathrm{R}$ (2002) Tau-mediated cytotoxicity in a pseudohyperphosphorylation model of Alzheimer's disease. J. Neurosci. 15: 9733-9741

26. Mills JC, Lee VMY and Pittman R (1998) Activation of a PP2A-like phosphatase and dephosphorylation of tau characterize onset of the execution phase of apoptosis. J. Cell Sci. 111: 625-636

27. Mookherjee P and Johnson GV (2001) Tau phosphorylation during apoptosis of human SH-SY5Y neuroblastoma cells. Brain Res. 921: 31-43

28. Lorio G, Avila J and Diaz-Nido J (2001) Modifications of tau protein during neuronal cell death. J. Alzheimer's Dis. 3: 563-575

29. Stoothoff WH and Johnson GV (2001) Hyperosmotic stress-induced apoptosis and tau phosphorylation in human neuroblastoma cells. J. Neurosci. Res. 65: 573-582

30. Gallo V, Giovannini C and Levi G (1980) Modulation of non-N-methyl-Daspartate receptors in cultured cerebellar granule cells. J. Neurochem. 54: $1619-1625$

31. D'Mello SR, Galli C, Ciotti T and Calissano P (1993) Induction of apoptosis in cerebellar granule neurons by low potassium: inhibition of death by insulin-like growth factor I and CAMP. Proc. Natl. Acad. Sci. USA 90: 10989-10993

32. Galli C, Meucci O, Scorziello A, Werge TM, Calissano P and Schettini G (1995) Apoptosis in cerebellar granule cells is blocked by high $\mathrm{KCl}$, forskolin, and IGF1 through distinct mechanisms of action: the involvement of intracellular calcium and RNA synthesis. J. Neurosci. 15: 1172-1179

33. Steller H (1995) Mechanism and genes of cellular suicide. Science 267: 14451449

34. Cohen GM (1997) Caspase: the executioners of apoptosis. Biochem. J. 326: 116

35. Eldadah BA, Yakovlev AG and Faden AI (1997) The role of CED-3-related cysteine proteases in apoptosis of cerebellar granule cells. J. Neurosci. 17: 6105-6113

36. Canu N, Barbato C, Ciotti MT, Serafino A, Dus L and Calissano P (2000) Proteasome involvement and accumulation of ubiquitinated proteins in cerebellar granule neurons undergoing apoptosis. J. Neurosci. 20: 589-599

37. Armstrong RC, Aja TJ, Hoang KD, Gaur S, Bai X, Alnemri ES, Litwack G, Karanewsky DS, Fritz LC and Tomaselli KJ (1997) Activation of the CED3/ICErelated protease CPP32 in cerebellar granule neurons undergoing apoptosis but not necrosis. J. Neurosci. 17: 553-562

38. Allsopp TE, McLuckie J, Kerr LE, Macleod M, Sharkey J and Kelly JS (2000) Caspase 6 activity initiates caspase 3 activation in cerebellar granule cell apoptosis. Cell Death Differ. 7: 984-993

39. Vaillant AR, Mazzoni I, Tudan C, Boudreau M, Kaplan DR and Miller FD (1999) Depolarization and neurotrophins converge on the phosphatidylinositol 3kinase-Akt pathway to synergistically regulate neuronal survival. Cell Biol. 146: 955-966

40. Dudek H, Datta SR, Franke TF, Birnbaum MJ, Yao R, Cooper GM, Segal RA, Kaplan DR and Greenberg ME (1997) Regulation of neuronal survival by the serine-threonine protein kinase Akt. Science 275: 661-665

41. Miller TM, Tansey MG, Johnson Jr EM and Creedon DJ (1997) Inhibition of phosphatidylinositol 3-kinase activity blocks depolarization- and insulin-like growth factor I-mediated survival of cerebellar granule cells. J. Biol. Chem. 272: 9847-9853

42. Vitolo OV, Ciotti MT, Galli C, Borsello T and Calissano P (1998) Adenosine and ADP prevent apoptosis in cultured rat cerebellar granule cells. Brain Res. 809: 297-301

43. Lafon-Cazal M, Pietri S, Culcasi M and Bockarert J (1993) NMDA-dependent superoxide production and neurotoxicity. Nature 364 : 535-537 
44. Dugan LL, Sensi LS, Canzoniero LM, Handran SD, Rotham SM, Lin TS, Goldeberg MP and Choi DW (1995) Mitochondrial production of reactive oxigens in cortical neurons following exposure to $\mathrm{N}$-methyl-D-aspartate. J. Neurosci. 15: 6377-6388

45. De Silva R and Farrer M (2002) Tau neurotoxicity without lesions: a fly challenges a tangled web. Trends Neurosci. 7: 327-329

46. Lee G, Newman ST, Gard DL, Band H and Panchamoorthy G (1988) Tau interacts with src-family non-receptor tyrosine kinases. J. Cell Sci. 111: 31673177

47. D'Mello SR, Borodezt K and Soltoff SP (1997) Insulin-like growth factor and potassium depolarization maintain neuronal survival by distinct pathways: possible involvement of PI 3-kinase in IGF-1 signaling. J. Neurosci. 17: 15481560

48. Franke TF, Kaplan DR, Cantley LC and Toker A (1997) Direct regulation of the Akt proto-oncogene product by phosphatidylinositol-3,4-bisphosphate. Science 275: 665-668

49. Lee CW, Lau KF, Miller CC and Shaw PC (2003) Glycogen synthase kinase-3 beta-mediated tau phosphorylation in cultured cell lines. Neuroreport 14: 257260

50. Singh SS, Chauhan A, Murkami N and Chauhan VP (1996) Profilin and gelsolin stimulate phosphatidylinositol 3-kinase activity. Biochemistry 35 : 16544-16549

51. Maas T, Eidenmuller $J$ and Brandt $R(2000)$ Interaction of tau with the neuronal membrane cortex is regulated by phosphorylation sites that are modified in paired helical filaments. J. Biol. Chem. 275: 15733-15740

52. Carmel G, Mager EM, Binder LI and Kuret J (1996) The structural basis of monoclonal antibody Alz50's selectivity for Alzheimer's disease pathology. J. Biol. Chem. 271: 32789-32795

53. Abraha A, Ghoshal N, Gamblin TC, Cryns V, Berry RW, Kuret J and Binder LI (2000) C-terminal inhibition of tau assembly in vitro and in Alzheimer's disease. J. Cell Sci. 21: 3737-3745

54. Greenberg SG and Davies P (1990) A preparation of Alzheimer paired helical filaments that displays distinct tau proteins by polyacrylamide gel electrophoresis. Proc. Natl. Acad. Sci. USA 87: 5827-5831
55. Hoffmann R, Lee VM, Leight S, Varga I and Otvos Jr L (1997) Unique Alzheimer's disease paired helical filament specific epitopes involve double phosphorylation at specific sites. Biochemistry 36: 8114-8124

56. Goedert M, Jakes R, Crowther RA, Six J, Lubke U, Vandermeeren M, Cras P, Trojanowski JQ and Lee VM (1993) The abnormal phosphorylation of tau protein at Ser-202 in Alzheimer disease recapitulates phosphorylation during development. Proc. Natl. Acad. Sci. USA 90: 5066-5070

57. Roth MB, Zahler AM and Stolk JA (1991) A conserved family of nuclear phosphoproteins localized to sites of polymerase II transcription. J. Cell Biol. 115: $587-596$

58. Graham FL and van der Eb A (1973) A new technique for the assay of infectivity of human adenovirus 5 DNA. Virology 52: 456-476

59. Rosenfeld MA, Yoshimura K, Trapnell BC, Yoneyama K, Rosenthal ER, Dalemans W, Fukayama M, Bargon J, Stier LE and Stratford-Perricaudet L (1992) In vivo transfer of the human cystic fibrosis transmembrane conductance regulator gene to the airway epithelium. Cell 68: 143-155

60. Levi G, Aloisi F, Ciotti M T and Gallo V (1984) Autoradiographic localization and depolarization-induced release of acidic aminoacids differentiating cerebellar granule cells cultures. Brain Res. 290: 77-86

61. Soto AM and Sonnenschein C (1985) The role of estrogen on the proliferation of human breast tumor cells (MCF-7). J. Steroid Biochem. 23: 87-94

62. Volonte C, Ciotti MT and Battistini L (1994) Development of a method for measuring cell number: application to CNS primary neuronal culture. Cytometry 17: 274-276

63. Manthrope M, Fagnani R, Skaper SD and Varon S (1986) An automated colorimetric microassay for neuronotrofic factor. Brain Res. 390: 191-198

64. Lee G (1997) Expression of map cDNAs in eukaryotic cells. In Brain Microtubule Associated Proteins: Modifications in Disease Avila J, Brandt R and Kosik KS (eds) Amsterdam, Netherlands: Harwood Academic Publishers, pp 293-311

65. Lu M and Kosik KS (2001) Competition for microtubule binding with dual expression of tau missense and splice isoforms. Mol. Biol. Cell 12: 171-184

66. Laemmli UK (1970) Cleavage of structural proteins during assembly of the head of bacteriophage T4. Nature 227: 682-685 